\title{
Characterization of amphoteric bentonite-loaded magnetic biochar and its adsorption properties for $\mathrm{Cu}^{2+}$ and tetracycline
}

\author{
Hongyan Deng ${ }^{\text {Equal first author, } 1}$, Haixia He ${ }^{\text {Equal first author, } 1}{ }^{1}$ Wenbin $\mathbf{L i}^{\text {Corresp., } 1}$, Touqeer Abbas ${ }^{2}$, Zhifeng Liu ${ }^{3}$ \\ ${ }^{1}$ College of Environmental Science and Engineering, China west normal university, Nanchong, China \\ 2 Key Laboratory of Environment Remediation and Ecological Health, Ministry of Education, Zhejiang University, Zhejiang, China \\ 3 Qinba Mountains of Bio-Resource Collaborative Innovation Center of Southern Shaanxi province, Hanzhong, China \\ Corresponding Author: Wenbin Li \\ Email address: Iwb062@cwnu.edu.cn
}

To realize simultaneous adsorption of heavy metal and antibiotic pollutants by a BC-based recyclable material, $\mathrm{Fe}_{3} \mathrm{O}_{4}$ magneti c biochar (MBC) was prepared by co-precipitation method. Then different ratios of dodecyl dimethyl betaine (BS-12) -modified bentonite (BS$B$ ) were loaded on the surfaces of biochar $(B C)$ and $M B C$ to prepare $B S-B$-loaded BC and MBC composites, called BS-B/BC and BS-B/MBC, respectively. The physicochemical and structural properties of the composites were characterized by scanning electron microscopy, Fourier transform infrared spectrometry, thermogravimetric analysis, specific surface area $\left(\mathrm{S}_{\mathrm{BET}}\right)$ analysis, and vibrating sample magnetometry, and the adsorption efficiencies of $B S-B / B C$ and $B S-B / M B C$ to $\mathrm{Cu}^{2+}$ and tetracycline (TC) $w$ ere studied. The following results were obtained. (1) Compared with BS-B/BC, BS-B/MBC had decreased $\mathrm{pH}$ and cation exchange capacity (CEC) and increased $\mathrm{S}_{\mathrm{BET}}$. The $\mathrm{pH}, \mathrm{CEC}$, and $\mathrm{S}_{\mathrm{BET}}$ of $\mathrm{BS}-\mathrm{B} / \mathrm{BC}$ and $\mathrm{BS}-\mathrm{B} / \mathrm{MBC}$ decreased with the increase in the BS-12 proportion of BS-B. The surface of $\mathrm{BS}-\mathrm{B} / \mathrm{MBC}$ became rough a fter $\mathrm{Fe}_{3} \mathrm{O}_{4}$ loading. (2) The residual rate of $\mathrm{BS}-\mathrm{B} / \mathrm{MBC}$ was higher than that of $\mathrm{BS}-\mathrm{B} / \mathrm{BC}$ a fter high-temperature combustion, and the residual rate decreased with the increase in the BS-12 proportion of BS-B. The 2D infrared spectra showed that $\mathrm{Fe}_{3} \mathrm{O}_{4}$ and $\mathrm{BS}-12$ were modified on the surface of $\mathrm{BS}-\mathrm{B} / \mathrm{MBC}$. MBC and BS-B/MBC had splendid magnetism and could be separated by external magnetic field. (3) Compared with unmagnetized ones, the adsorption effects of $\mathrm{Cu}^{2+}$ and TC on different BS-B/MBCS improved, and the average adsorption rate reached the largest value of $91.92 \%$ and 97.76 $\%$, respectively. $\mathrm{Cu}^{2+}$ and TC adsorptions were spontaneous, endothermic, and entropyincreasing processes. The $\mathrm{pH}$ and $\mathrm{S}_{\mathrm{BET}}$ of the material had a great influence on $\mathrm{Cu}^{2+}$ and TC adsorptions, respectively, than CEC. 
1 Characterization of amphoteric bentonite-loaded magnetic biochar

2

3

4

5

6

7

8

\section{and its adsorption properties for $\mathrm{Cu}^{2+}$ and tetracycline}

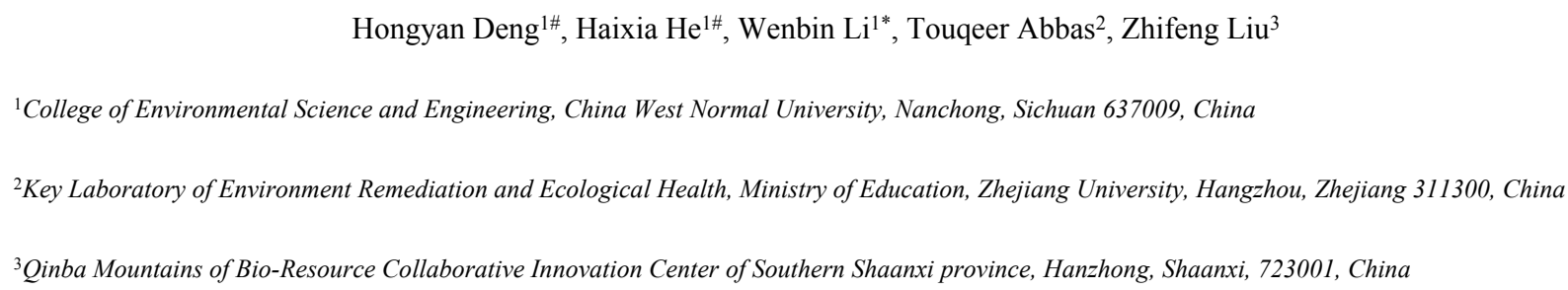

\section{ABSTRACT}

To realize simultaneous adsorption of heavy metal and antibiotic pollutants by a BC-based recyclable material, $\mathrm{Fe}_{3} \mathrm{O}_{4}$ magnetic biochar (MBC) was prepared by co-precipitation method. Then different ratios of dodecyl dimethyl betaine (BS-12)-modified bentonite (BS-B) were loaded on the surfaces of biochar (BC) and $\mathrm{MBC}$ to prepare $\mathrm{BS}-\mathrm{B}-$ loaded $\mathrm{BC}$ and $\mathrm{MBC}$ composites, called $\mathrm{BS}-\mathrm{B} / \mathrm{BC}$ and $\mathrm{BS}-\mathrm{B} / \mathrm{MBC}$, respectively. The physicochemical and structural properties of the composites were characterized by scanning electron microscopy, Fourier transform infrared spectrometry, thermogravimetric analysis, specific surface area $\left(\mathrm{S}_{\mathrm{BET}}\right)$ analysis, and vibrating sample magnetometry, and the adsorption efficiencies of $\mathrm{BS}-\mathrm{B} / \mathrm{BC}$ and $\mathrm{BS}-\mathrm{B} / \mathrm{MBC}$ to $\mathrm{Cu}^{2+}$ and tetracycline (TC) were studied. The following results were obtained. (1) Compared with BS-B/BC, BS-B/MBC had decreased $\mathrm{pH}$ and cation exchange capacity (CEC) and increased $\mathrm{S}_{\mathrm{BET}}$. The $\mathrm{pH}$, CEC, and $\mathrm{S}_{\mathrm{BET}}$ of $\mathrm{BS}-\mathrm{B} / \mathrm{BC}$ and $\mathrm{BS}-\mathrm{B} / \mathrm{MBC}$ decreased with the increase in the BS-12 proportion of BS-B. The surface of BS-B/MBC became rough after $\mathrm{Fe}_{3} \mathrm{O}_{4}$ loading. (2) The residual rate of $\mathrm{BS}-\mathrm{B} / \mathrm{MBC}$ was higher than that of BS$\mathrm{B} / \mathrm{BC}$ after high-temperature combustion, and the residual rate decreased with the increase in the BS-12 proportion of BS-B. The 2D infrared spectra showed that $\mathrm{Fe}_{3} \mathrm{O}_{4}$ and BS-12 were modified on the surface of BS-B/MBC. MBC and $\mathrm{BS}-\mathrm{B} / \mathrm{MBC}$ had splendid magnetism and could be separated by external magnetic field. (3) Compared with 
27

unmagnetized ones, the adsorption effects of $\mathrm{Cu}^{2+}$ and TC on different BS-B/MBCs improved, and the average adsorption rate reached the largest value of $91.92 \%$ and $97.76 \%$, respectively. $\mathrm{Cu}^{2+}$ and $\mathrm{TC}$ adsorptions were spontaneous, endothermic, and entropy-increasing processes. The $\mathrm{pH}$ and $\mathrm{S}_{\mathrm{BET}}$ of the material had a great influence on $\mathrm{Cu}^{2+}$ and $\mathrm{TC}$ adsorptions, respectively, than CEC.

Keywords: Magnetized biochar; Bentonite; Dodecyl dimethyl betaine; Surface characteristics; Adsorption capacity

\section{INTRODUCTION}

Heavy metal and antibiotics in livestock farm wastewater has become one of the focuses of research (Nyamukamba et al., 2019). The metabolites of heavy metals and antibiotics have strong persistence, difficult degradation, and easy accumulation; can exist in water and soil environment for a long time; and eventually threaten human health through the food chain (Khan et al., 2015; Min et al., 2015). Therefore, screening remediation materials with high adsorption capacity and good recycling performance for heavy metal and antibiotic have great importance for the pollution control of livestock and poultry breeding and the sustainable development of agriculture.

The remediation methods for water pollution include physical, chemical, and biological remediation (Mazurkiewicz et al., 2020; Zulfiqar et al., 2021; Kumar et al., 2021). Among which, material adsorption has become a hot spot in pollution remediation research because of its simple operation, low cost, and obvious effect (Fu et al., 2019; Isakovski et al., 2020; Kumar et al., 2021). Many repair materials, such as biochar (BC) (Ahmad et al., 2014; He et al., 2019), clay minerals (Beraa et al., 2016), and agricultural and forestry wastes (Garg et al., 2021), have been studied. The surface of BC contains a large number of negatively charged functional groups, which greatly adsorb heavy metals and organic pollutants in water environment (Mohan et al., 2014; Yang et al., 2016). The adsorption capacities of straw BC for $\mathrm{Cd}^{2+}$ and methylene blue are 30.19 and $46.60 \mathrm{mg} / \mathrm{g}$, respectively (Park et al., 2016; Li et al., 2016a). Feng et al. (2020) found that the adsorption capacity of bamboo-willow $\mathrm{BC}$ for oxytetracycline and sulfaethoxazole are 11.98 and $10.12 \mathrm{mg} / \mathrm{g}$, respectively. The adsorption isotherm models of $\mathrm{BC}$ for phenol and tannic acid are multilayer and monolayer, respectively (Lawal et al., 2021). BC materials have good adsorption effect on pollutants but are difficult to separate in aqueous solution. Some researchers loaded magnetic particles on the surface of $\mathrm{BC}$ by $\mathrm{Fe}_{3} \mathrm{O}_{4}$, and 
54

55

56

57

58

59

60

realized the separation of $\mathrm{BC}$ material in solution by magnetic force. Then, the pollutants absorbed on the magnetic biochar (MBC) are eluted for the recycling of the MBC (Yan et al., 2015; Wang et al., 2020). Studies have shown that $\mathrm{MBC}$ can form a weak magnetic field around them to improve the metabolic capacity of microorganisms, accelerate the decomposition of pollutants, and thus reduce the concentrations of pollutants (Kastner et al., 2015; Kyung-Won et al., 2016).

Bentonite (B) has strong adsorption capacity, ion exchange capacity and expansibility as a good pollution remediation material (Said and Goda, 2021). Current research on organic B focuses on its modification using surfactants to enhance its adsorption and fixation of pollutants. Amphoteric surface modifiers have hydrophilic positive and negative charges and hydrophobic carbon chains, which can adsorb organic and heavy metal pollution, simultaneously. Therefore, using amphoteric surface modifiers to modify B can simultaneously improve the adsorption performance of B to organic matter and heavy metals (Li et al., 2016b). The adsorption amounts of $\mathrm{Cd}^{2+}$ and phenol on Lou soil modified by amphoteric surface modifier (BS-12) were 1.3-1.8 and 4.0-8.3 times higher than those on unmodified soil sample, respectively (Meng et al., 2007). The magnetization method realizes the secondary utilization of BC but does not improve its adsorption capacity for pollutants (He et al., 2019; Wang et al., 2020). Therefore, loading amphoteric B on MBC can greatly improve the adsorption capacity of the $\mathrm{MBC}$ to various pollutants and realize the recycling of the material synchronously.

Alternanthera philoxeroides BC and BS-12-modified B (BS-B) were prepared by oxygen-limiting hightemperature pyrolysis and wet method, respectively, and $\mathrm{MBC}$ was prepared by co-precipitation method to verify the absorption effect of BS-B-loaded MBC (BS-B/MBC) on heavy metal and antibiotic pollution. Then, BS-B-loaded BC (BS-B/BC) and BS-B/MBC were prepared by separately loading BS-B on the surfaces of BC and $\mathrm{MBC}$, and the properties and structure of the composite materials were characterized. In addition, the isothermal adsorption and thermodynamic characteristics of $\mathrm{Cu}^{2+}$ and tetracycline (TC) on the composite materials were studied to provide a reference for the application of BC-based composite materials in sewage treatment.

\section{MATERIALS AND METHODS}

\section{Materials}


81

Dodecyl dimethyl betaine was used as the amphoteric modifier, which abbreviated as BS-12 (AR, produced by Tianjin Xingguang Reagent Factory, Tianjin City, China). The B used was sodium B, which purchased from Henan Xinyang Bentonite Produce Company and purified by washing method before use (Shah et al., 2018). The basic physicochemical properties of the purified B are: cation exchange capacity (CEC) is $1000.33 \mathrm{mmol} / \mathrm{kg}$, $\mathrm{pH}$ is 9.59 , and total organic carbon (TOC) is $4.98 \mathrm{~g} / \mathrm{kg}$. $\mathrm{FeCl}_{3} \cdot 6 \mathrm{H}_{2} \mathrm{O}, \mathrm{FeSO}_{4} \cdot 7 \mathrm{H}_{2} \mathrm{O}$ and $\mathrm{NaOH}$ were all purchased from Chengdu Kelong Chemical Reagent Factory, Chengdu City, Sichuan Province, China. TC was purchased from Sigma (USA) and had a purity of $99.9 \% . \mathrm{Cu}^{2+}$ solution was used as pollutant, and the solution was prepared by using $\mathrm{CuSO}_{4} \cdot 5 \mathrm{H}_{2} \mathrm{O}$ (analytical reagent) purchased from Chengdu Kelon Chemical Reagent Factory. Fig. 1A and 1B show the structural formula of BS-12 and TC, respectively.

BS-B was prepared by wet method (Li et al., 2016b). BS-12 solution was added into $10 \mathrm{~g}$ of purified B (the mass ratio between solution and soil was 10:1), then reacted for $6 \mathrm{~h}$ at $40{ }^{\circ} \mathrm{C}$; Centrifuged at $4800 \mathrm{r} / \mathrm{min}$ for 10 min, washed 3 times with deionized water $\left(\mathrm{dH}_{2} \mathrm{O}\right)$, dried, grinded and sieved through 60 -mesh nylon sieve to obtain BS-B. The amount use of BS-12 modifier was defined by Eq. (1):

$$
W=m \times \mathrm{CEC} \times \mathrm{M} \times 10^{-6} \times R_{\mathrm{BS}} / C_{\mathrm{BS}}
$$

where $W_{\mathrm{BS}}$ stands for the mass $(\mathrm{g})$ of BS-12; $m$ stands for the mass $(\mathrm{g})$ of bentonite; CEC stands for the cation exchange capacity of the bentonite $(\mathrm{mmol} / \mathrm{kg}) ; M_{\mathrm{BS}}$ stands for the relative molar mass of BS-12 $(\mathrm{g} / \mathrm{mol}) ; R_{\mathrm{BS}}$ stands for the modification ratio $\left(50 \%\right.$ or $100 \%$ ) of BS- $12 ; C_{\mathrm{BS}}$ stands for the content (mass fraction) of BS- 12 .

A. philoxeroides was washed with $\mathrm{dH}_{2} \mathrm{O}$, dried to constant weight under $60{ }^{\circ} \mathrm{C}$, grinded and sieved through a 200 -mesh nylon sieve, and fired for $8 \mathrm{~h}$ under $400{ }^{\circ} \mathrm{C}$ by oxygen-limiting high-temperature pyrolysis to obtain BC. Co-precipitation method was used to prepare MBC (He et al., 2019). In this method, $20.00 \mathrm{~g} \mathrm{BC}$ was dispersed in $2.0 \mathrm{~L} \mathrm{dH}_{2} \mathrm{O}$ and stirred for $30 \mathrm{~min}$. Under strictly anaerobic conditions, $0.4 \mathrm{M} \mathrm{FeCl}_{3} \cdot 6 \mathrm{H}_{2} \mathrm{O}$ and $0.2 \mathrm{M} \mathrm{FeSO}_{4} \cdot 7 \mathrm{H}_{2} \mathrm{O}$ were successively added to $60{ }^{\circ} \mathrm{C}$ water, fully stirred for $2 \mathrm{~h}$, and heated to $75^{\circ} \mathrm{C}$. The $\mathrm{pH}$ was adjusted to 10 with $5 \mathrm{~mol} / \mathrm{L} \mathrm{NaOH}$ solution and the $\mathrm{MBC}$ was separated by magnets after continuous stirring for $1 \mathrm{~h}$ and natural cooling. MBC was obtained after washing several times with $\mathrm{dH}_{2} \mathrm{O}$. MBC was dried at $60{ }^{\circ} \mathrm{C}$ and then passed through a 60 -mesh sieve. A wet process was used to prepare BS-B/BC and BS$\mathrm{B} / \mathrm{MBC}$. In this process, $100 \mathrm{~g} \mathrm{BC}$ or $\mathrm{MBC}$ was slowly added to $1.0 \mathrm{~L} \mathrm{dH}_{2} \mathrm{O}$, and $\mathrm{BS}-\mathrm{B}$ was added again. After stirring at $40{ }^{\circ} \mathrm{C}$ for $3 \mathrm{~h}$, the samples were separated, washed by $\mathrm{dH}_{2} \mathrm{O}$ thrice and dried at $60{ }^{\circ} \mathrm{C}$. Then, BS$\mathrm{B} / \mathrm{BC}$ and $\mathrm{BS}-\mathrm{B} / \mathrm{MBC}$ were dried at $60^{\circ} \mathrm{C}$ for $12 \mathrm{~h}$ and passed through a 60 -mesh sieve. 
108

109

110

111

112

113

114

115

116

117

118

119

120

121

122

123

124

125

126

127

128

\section{Experimental design}

BS-B samples with BS-12 proportions of $0 \%, 50 \%$, and $100 \%$ were prepared and named as B (bentonite only), 50BS-B, and 100BS-B, respectively. $\mathrm{BC}$ and $\mathrm{MBC}$ were used as the control (CK). BC, B/BC, 50BS$\mathrm{B} / \mathrm{BC}, 100 \mathrm{BS}-\mathrm{B} / \mathrm{BC}, \mathrm{MBC}, \mathrm{B} / \mathrm{MBC}, 50 \mathrm{BS}-\mathrm{B} / \mathrm{MBC}$, and 100BS-B/MBC (8 samples in total) were analyzed for the $\mathrm{pH}, \mathrm{CEC}$, and Brunaer-Emmett-Telle specific surface area $\left(\mathrm{S}_{\mathrm{BET}}\right)$, and characterized by scanning electron microscopy (SEM), thermogravimetry (TG), Fourier transform infrared (FT-IR) spectroscopy, and vibration sample magnetometry (VSM).

The pre-experiment of $\mathrm{Cu}^{2+}$ adsorption showed that the adsorption isotherm began to turn at 300-400 $\mathrm{mg} / \mathrm{L}$, so the $\mathrm{Cu}^{2+}$ concentration in isothermal adsorption experiment was set to $0,20,50,100,150,200,300$, 400 , and $500 \mathrm{mg} / \mathrm{L}$ for a total of nine concentration gradients. The concentration of tetracycline was set to 0,2 , $5,10,20,40,60,80$, and $100 \mathrm{mg} / \mathrm{L}$ nine concentration gradients by their pre-experiment. Three replicates were set for each treatment.

\section{Experimental methods}

pH value was determined using a HQ411D table pH meter (Hash Company, USA; refer to the test method of soil sample, solid-liquid ratio was 1:5). CEC was determined by sodium acetate-ammonium acetate method. $\mathrm{S}_{\mathrm{BET}}$ was analyzed by by multi-point BET method using a V-Sorb2800P analyzer. SEM was performed using a Japanese Hitachi S-4800 scanning electron microscope. TG was performed using a STA449F3 synchronous thermal analyzer (NETZSCH) under the following conditions: temperature range $25-900{ }^{\circ} \mathrm{C}$; sample quality, 10-15 mg; heating rate, $10{ }^{\circ} \mathrm{C} / \mathrm{min} ; \mathrm{N}_{2}$ atmosphere. FT-IR analysis was performed on a Nicolet 5DX type Fourier transform infrared spectrometer, and the 2D FTIR spectra were analyzed by 2DShige software. Magnetic curves were determined by Lakeshore 665 VSM method.

Nine samples $(0.5000 \mathrm{~g})$ of each composite material were separately packed in $50 \mathrm{~mL}$ plastic centrifuge tubes, added with $20 \mathrm{~mL}$ of $\mathrm{Cu}^{2+}$ (TC) solutions under different concentration gradients, shaken at room temperature for $12 \mathrm{~h}(200 \mathrm{r} / \mathrm{min})$, and centrifuged at $4800 \mathrm{r} / \mathrm{min}$ for $15 \mathrm{~min}$. The supernatant was collected to determine the $\mathrm{Cu}^{2+}$ (TC) concentration, and the actual adsorption amount of the test material was calculated by subtraction (Zhang et al., 2020; Zou et al., 2020). The experiments were carried out at 20 and $40{ }^{\circ} \mathrm{C}$ respectively for calculating the thermodynamic parameters of $\mathrm{Cu}^{2+}$ and $\mathrm{TC}$ adsorptions. $\mathrm{The}^{2+} \mathrm{Cu}^{2+}$ content was 
135

136

137 138

determined via flame atomic absorption spectrophotometry, and background absorption was corrected through the Zeeman effect. The TC concentration was determined by SP-2100 UV-VIS spectrophotometer at $365 \mathrm{~nm}$.

The above measurements were all inserted into standard solutions for analysis quality control.

\section{Data processing}

The equilibrium adsorption amount of $\mathrm{Cu}^{2+}$ and TC was calculated using Eq. (2):

$$
q=\frac{V \times\left(C_{0}-C_{\mathrm{e}}\right)}{W_{0}}
$$

where $C_{0}(\mathrm{mmol} / \mathrm{L})$ and $C_{\mathrm{e}}(\mathrm{mmol} / \mathrm{L})$ are the initial and equilibrium concentrations of $\mathrm{Cu}^{2+}(\mathrm{or} \mathrm{TC})$ in the solution, respectively. $V(\mathrm{~mL})$ is the volume of $\mathrm{Cu}^{2+}($ or $\mathrm{TC})$ solution added. $W_{0}(\mathrm{~g})$ is the weight of the tested material. $q(\mathrm{mmol} / \mathrm{kg})$ is the equilibrium adsorption amount of $\mathrm{Cu}^{2+}$ (or TC) on the tested material.

The adsorption rate $A R(\%)$ of $\mathrm{Cu}^{2+}$ and TC was calculated using Eq. (3):

$$
A R=\frac{100 \times\left(C_{0}-C_{\mathrm{e}}\right)}{C_{0}}
$$

The Langmuir isotherm was selected on the basis of the adsorption isotherm trend and the isothermal equation [Eq. (4)] is as follows (Zhang et al., 2020):

$$
q=\frac{q_{\mathrm{m}} b C_{\mathrm{e}}}{1+b C_{\mathrm{e}}}
$$

where $q_{\mathrm{m}}$ indicates the maximum adsorption amount of $\mathrm{Cu}^{2+}$ (or TC) on the different materials, $\mathrm{mmol} / \mathrm{kg} ; b$ represents the apparent equilibrium constant of the $\mathrm{Cu}^{2+}$ (or TC) adsorption, which can be used to measure the affinity of adsorption.

Parameter $b$ in the Langmuir model is equivalent to the apparent adsorption constant of equilibrium constant, and the thermodynamic parameter calculated by $b=K$ or $K_{\mathrm{a}}$ is called the apparent thermodynamic parametes; Equations (5-7) are as follows (Zhao et al., 2021):

$$
\begin{gathered}
\Delta G=-R T \ln K \\
\Delta H=R\left(\frac{T_{1} \cdot T_{2}}{T_{2}-T_{1}}\right) \cdot \ln \left(\frac{K_{a}, T_{2}}{K_{a}, T_{1}}\right)
\end{gathered}
$$




$$
\Delta S=\frac{\Delta H-\Delta G}{T}
$$

152

where $\Delta G$ is the standard free energy change $(\mathrm{kJ} / \mathrm{mol}), R$ is a constant $(8.3145 \mathrm{~J} / \mathrm{mol} / \mathrm{K}), T$ is the adsorption temperature $\left(\mathrm{T}_{1}=293.16 \mathrm{~K}, \mathrm{~T}_{2}=313.6 \mathrm{~K}\right), \Delta H$ is the enthalpy of adsorption process $(\mathrm{kJ} / \mathrm{mol})$, and $\Delta S$ is the entropy change of adsorption process $(\mathrm{J} / \mathrm{mol} / \mathrm{K})$.

CurveExpert 1.4 fitting software was used in isothermal fitting, and SigmaPlot 10.0 software was adopted to improve data plotting. SPSS 16.0 statistical analysis software was used to process the experimental data for variance and correlation analysis ( $\mathrm{Li}$ et al., 2020). SigmaPlot 10.0 software was adopted to improve data plotting. The data were expressed as the means with standard deviation, and different letters indicate significant differences among various amendments (Lopez et al., 2012). Analysis of variance was performed to determine the effects of amendments, followed by Tukey's honestly significant difference test. Differences of $p<0.05$ were considered significant (Ana et al., 2013).

\section{RESULTS}

\section{Basic physicochemical properties of the tested materials}

Figure 2 shows the physicochemical characteristics of each test material. The $\mathrm{pH}$ and $\mathrm{CEC}$ of $\mathrm{BC}$ increased when B was loaded but decreased when BS-B was loaded, and the amplitude decreased with the increase in the BS-12 proportion of BS-B. $\mathrm{S}_{\mathrm{BET}}$ decreased when $\mathrm{BC}$ was loaded with $\mathrm{B}$ and $\mathrm{BS}-\mathrm{B}$, and further decreased with the increase in the modification ratio of BS-12 on BS-B. $\mathrm{B} / \mathrm{BC}$ had a slight increase in $\mathrm{pH}$ and a higher increase in CEC, which may be caused by the similar $\mathrm{pH}$ and larger $\mathrm{CEC}$ of $\mathrm{B}$ than those of BC. BS12 on BS-B can neutralize the alkalinity of B, and the long carbon chains of BS-12 can cover the surface of B and thus reduce the $\mathrm{CEC}$ of $\mathrm{BS}-\mathrm{B}$. Therefore, when $\mathrm{BC}$ was loaded with $\mathrm{BS}-\mathrm{B}$, the $\mathrm{pH}$ and $\mathrm{CEC}$ of $\mathrm{BS}-\mathrm{B} / \mathrm{BC}$ materials decreased with the increase in the modification ratio of BS-12. Moreover, when BC was loaded with BS-B, the interlayer or surface pores of BC were covered by BS-B, which increased the average particle size of $\mathrm{BS}-\mathrm{B} / \mathrm{BC}$ and resulted in the decrease in $\mathrm{S}_{\mathrm{BET}}$. Compared with the unmagnetized ones, the magnetized materials had slightly reduced $\mathrm{pH}$ and $\mathrm{CEC}$ and remarkably increased $\mathrm{S}_{\mathrm{BET}}$ because the increase in $\mathrm{Fe}_{3} \mathrm{O}_{4}$ particles increased the roughness of a material's surface and then increased its surface area (He et al., 2019).

\section{SEM images of the test materials}



surface and a regular pore structure. When $\mathrm{BC}$ surface was loaded with $\mathrm{B}$, the surface of $\mathrm{B} / \mathrm{BC}$ became rough, a few number of $\mathrm{B}$ particles were attached to the surface of $\mathrm{BC}$, and some pores were also filled with $\mathrm{B}$ particles. When $\mathrm{BC}$ was loaded with 100BS-B, the surface smoothness of 100BS-B/BC increased, because the hydrophobic long carbon chain of BS-12 could form a layer of organic phase on the surface of 100BS-B, which could decreased the surface roughness (Zhang et al., 2020). When each composite material was loaded with $\mathrm{Fe}_{3} \mathrm{O}_{4}$, its surface became rough compared with the unmagnetized ones. A large number of $\mathrm{Fe}_{3} \mathrm{O}_{4}$ particles were attached to the surface of the material, and some pores were also filled with $\mathrm{Fe}_{3} \mathrm{O}_{4}$ particles. The results show that $\mathrm{Fe}_{3} \mathrm{O}_{4}$ had a large effect on the surface morphology of the magnetic material, and the iron oxide particles were dispersed on the carbon matrix, which increased the $\mathrm{S}_{\mathrm{BET}}$ (Xin et al., 2017).

187

\section{TG analysis of the tested materials}

The TG curves of the different materials are shown in Fig. 4. The test materials had different degrees of weight loss after high-temperature pyrolysis $\left(900{ }^{\circ} \mathrm{C}\right)$, and the weight loss rates of the materials were greater after magnetization. The weight loss of the test materials is in the order: $\mathrm{BC}>100 \mathrm{BS}-\mathrm{B} / \mathrm{BC}>50 \mathrm{BS}-\mathrm{B} / \mathrm{BC}>\mathrm{B} / \mathrm{BC}, 100 \mathrm{BS}-$ $\mathrm{B} / \mathrm{MBC}>50 \mathrm{BS}-\mathrm{B} / \mathrm{MBC}>\mathrm{B} / \mathrm{MBC}>\mathrm{MBC}$. As the modification ratio of BS-12 increased, the weight loss rate of BS$\mathrm{B} / \mathrm{BC}$ and $\mathrm{BS}-\mathrm{B} / \mathrm{MBC}$ materials gradually increased, mainly because the surface active agent $\mathrm{BS}-12$ was decomposable organic matter (He et al., 2019). Change in the TG curve showed three stages at the temperatures of $0-250{ }^{\circ} \mathrm{C}, 250-600{ }^{\circ} \mathrm{C}$, and $600-900{ }^{\circ} \mathrm{C}$, which represente the material water loss, organic matter decomposition, and crystal layer collapse, respectively.

Table 1 shows the weight loss rate and differential thermogravimetric (DTG, mass change rate with time, $\% / \mathrm{min}$ ) peak temperature of each material in the three stages of the TG curve. The DTG peak temperatures of the test materials were kept between $67{ }^{\circ} \mathrm{C}$ and $81{ }^{\circ} \mathrm{C}$ in the water loss stage (Stage 1). The water loss rates of the test materials are in the order: 100BS-B/BC $(8.26 \%)>\mathrm{B} / \mathrm{BC}(8.07 \%)>50 \mathrm{BS}-\mathrm{B} / \mathrm{BC}(7.51 \%)>\mathrm{BC}(6.68 \%)>$ 100BS-B/MBC $(5.02 \%)>50 \mathrm{BS}-\mathrm{B} / \mathrm{MBC}(4.74 \%)>\mathrm{MBC}(4.59 \%)>\mathrm{B} / \mathrm{MBC}(4.17 \%)$. In the organic carbon decomposition stage (Stage 2), the DTG peak temperatures of the test materials was kept between $400{ }^{\circ} \mathrm{C}$ and $530{ }^{\circ} \mathrm{C}$. The carbon loss rate of $\mathrm{BC}$ was only $11.6 \%$, whereas the carbon loss rates of the other test materials were in the range of $15.1 \%-23.48 \%$. Carbon loss rate increased with the increase in the modification ratio of 
204

205

206

207

208

209

210

211

212

213

214

215

216

217

218

219

220

221

222

223

224

225

226

227

228

229

230

BS-12. Almost no weight loss was observed in all the tested materials in the crystal layer collapse stage (Stage 3 ), and the DTG peak temperatures were in the range of $550-900{ }^{\circ} \mathrm{C}$. This part of weight loss change is only related to the composition and structure of the material itself and has nothing to do with the organic modification.

\section{FTIR and magnetic characteristics of the test materials}

The 2D infrared spectra of the test materials are shown in Fig. 5A (synchronous correlation diagram) and Fig. 5B (asynchronous correlation diagram), The red and blue marks in the figures indicate positive and negative reactions, respectively. The test materials presented a strong characteristic absorption peak of $\mathrm{Fe}-\mathrm{O}$ bond near $659-695 \mathrm{~cm}^{-1}$, which indicates that $\mathrm{Fe}_{3} \mathrm{O}_{4}$ was modified to the surface of $\mathrm{BC}$ materials. The peak in the vicinity of $990 \mathrm{~cm}^{-1}$ is the $\mathrm{O}-\mathrm{H}$ surface modal vibration absorption on the carboxyl group, which is related to the carboxyl group and the amine group in the BS-12 molecule. This result indicates that BS-12 bound to MBC. A characteristic absorption peak containing the $\mathrm{C}=\mathrm{O}$ functional group appeared at $1600 \mathrm{~cm}^{-1}$, and the deformation vibration characteristic absorption peak of the $\mathrm{C}-\mathrm{H}$ bond appeared near $2920 \mathrm{~cm}^{-1}$. The absorption peak at $3438 \mathrm{~cm}^{-1}$ was produced by the stretching vibration of the $-\mathrm{OH}$ bond. These results confirm that BS-B and $\mathrm{Fe}_{3} \mathrm{O}_{4}$ were loaded on the $\mathrm{BC}$ surface.

The results of the hysteresis curve in Fig. 6 show that $\mathrm{MBC}$ and $\mathrm{BS}-\mathrm{B} / \mathrm{MBC}$ have good magnetic separation performance. The saturation magnetization of $\mathrm{MBC}$ was $43 \mathrm{emu} / \mathrm{g}$. After BS-B loading, the magnetism of $\mathrm{BS}-\mathrm{B} / \mathrm{MBC}$ decreased slightly with the increase in BS-12 modification on BS-B. BS-B/MBC could still be separated by applying a magnetic field, which was of great importance for the recycling of BS$\mathrm{B} / \mathrm{MBC}$ materials.

\section{Isothermal adsorption and thermodynamic parameters of $\mathrm{Cu}^{2+}$}

The $\mathrm{Cu}^{2+}$ adsorption isotherms and adsorption rates of the test materials are shown in Fig. 7. The adsorption capacity of $\mathrm{Cu}^{2+}$ increased with the increase in equilibrium concentration, and the adsorption isotherm of the test materials to $\mathrm{Cu}^{2+}$ all conformed to the Langmuir model. $\mathrm{The}^{\mathrm{Cu}^{2+}}$ adsorption capacity of $\mathrm{BC}$ increased obviously after $\mathrm{B}$ loading. The $\mathrm{Cu}^{2+}$ adsorption capacity of $\mathrm{BS}-\mathrm{B} / \mathrm{MBC}$ increased with the increase in the modification ratio of BS-12 on BS-B. Compared with the unmagnetized ones, the magnetized materials had increased $\mathrm{Cu}^{2+}$ adsorption capacity. 
231

232

233

234

235

236

237

238

239

240

241

242

243

244

245

246

247

248

249

250

251

252

253

254

255

256

257

Table 2 shows the fitting parameters and thermodynamic parameters of $\mathrm{Cu}^{2+}$ adsorption by Langmuir model. The correlation coefficient reached an extremely significant level $(p<0.01)$. The maximum adsorption capacity $\left(q_{\mathrm{m}}\right)$ of different materials changed from $135.07 \mathrm{mmol} / \mathrm{kg}$ to $322.00 \mathrm{mmol} / \mathrm{kg}$. Compared with unmagnetized ones, the magnetized materials had higher $q_{\mathrm{m}}$ for $\mathrm{Cu}^{2+} .100 \mathrm{BS}-\mathrm{B} / \mathrm{MBC}$ had the best adsorption effect on $\mathrm{Cu}^{2+}$; its $q_{\mathrm{m}}$ reached $322.00 \mathrm{mmol} / \mathrm{kg}$, and its average adsorption rate $\left(A R_{\mathrm{e}}\right)$ was $91.92 \%$. The values of the adsorption constant $(b)$ of magnetized materials for $\mathrm{Cu}^{2+}$ were smaller than those of unmagnetized ones, which indicates that magnetization reduced the adsorption affinity of $\mathrm{BC}$ materials to $\mathrm{Cu}^{2+}$. This outcome might be due to the fact that $\mathrm{Fe}_{3} \mathrm{O}_{4}$ particles block the pores of $\mathrm{BC}$ materials, which results in the reduction of exchangeable cation sites on the surface. The $b$ values of $\mathrm{BS}-\mathrm{B} / \mathrm{BC}$ and $\mathrm{BS}-\mathrm{B} / \mathrm{MBC}$ were larger than those of $\mathrm{BC}$ and $\mathrm{MBC}$, which indicates that the adsorption affinity to $\mathrm{Cu}^{2+}$ became greater after BS-B loading. $\mathrm{B}$ had a larger $\mathrm{CEC}$ and could have an ion exchange reaction with more $\mathrm{Cu}^{2+}$, and $\mathrm{B}$ loading could promote $\mathrm{Cu}^{2+}$ adsorption. The value of $b$ was the largest when $\mathrm{BC}$ was loaded with B but decreased with the increasing in BS-12 modification rate on BS-B when BC was loaded with BS-B. This result indicates that BS-12 formed an organic coating on the surface of $\mathrm{BC}$ and reduced its adsorption affinity for $\mathrm{Cu}^{2+}$.

At 20 and $40{ }^{\circ} \mathrm{C}$, the Gibbs free energy $(\Delta G)$ values for the $\mathrm{Cu}^{2+}$ adsorption of each test material were less than 0 , which indicates that the adsorption was a spontaneous reaction. The adsorption enthalpy change $(\Delta H)$ of each tested material to $\mathrm{Cu}^{2+}$ was greater than 0 , which indicates that the adsorption was an endothermic reaction, and increasing temperature was conducive to the occurrence of adsorption. The entropy change $(\Delta S)$ of each test material was greater than 0 , which indicates that the disorder of the system in the $\mathrm{Cu}^{2+}$ adsorption process was increased by the tested materials.

\section{Isothermal adsorption and thermodynamic parameters of $\mathrm{TC}$}

Figure 8 shows the adsorption isotherm and adsorption rate of TC on the tested materials. The TC adsorption capacities of the materials increased with the increase in equilibrium concentration and were in accordance with the Langmuir model. Table 3 shows the Langmuir model fitting parameters for TC adsorption. The fitting of the TC adsorption isotherms of the test materials reached a very significant correlation level $(p<0.01)$. The $q_{\mathrm{m}}$ for TC adsorption changed from 118.60 to $602.83 \mathrm{mmol} / \mathrm{kg}, \mathrm{B} / \mathrm{MBC}$ had the best $q_{\mathrm{m}}$ for TC adsorption, and 50BS-B/MBC had the largest $A R_{\mathrm{e}}$ of $97.76 \%$. Compared with the unmagnetized materials, the magnetized 
258

259

260

261

262

263

264

265

266

267

268

269

270

271

272

273

274

275

276

277

278

279

280

281

282

283

materials could reach the TC adsorption equilibrium quickly and had higher $q_{\mathrm{m}}$ values for TC adsorption. After $\mathrm{B}$ and BS-B loading, the $b$ values of the materials for TC adsorption were larger than those of BC and MBC. At 20 and $40^{\circ} \mathrm{C}$, all test materials for $\mathrm{TC}$ adsorption had $\Delta G<0$, which indicates that the adsorption was a spontaneous reaction; $\Delta H>0$, which indicates that the adsorption was an endothermic reaction; and $\Delta S>0$, which indicates that the disorder of the system increased in the TC adsorption process.

\section{DISCUSSION}

\section{Correlation between adsorption and physicochemical properties}

The $q_{\mathrm{m}}$ and $A R_{\mathrm{e}}$ values of each test material for $\mathrm{Cu}^{2+}$ and TC were linearly fitted to the physicochemical properties of the material, and the fitting results are shown in Table 4. CEC had positive correlations with the $q_{\mathrm{m}}$ and $A R_{\mathrm{e}}$ for $\mathrm{Cu}^{2+}$ and TC adsorptions; $\mathrm{pH}$ and $\mathrm{S}_{\mathrm{BET}}$ had positive correlations with the $q_{\mathrm{m}}$ and $A R_{\mathrm{e}}$ for TC adsorption but had negative correlations with the $q_{\mathrm{m}}$ and $A R_{\mathrm{e}}$ for $\mathrm{Cu}^{2+}$ adsorption; $\mathrm{pH}$ had a negative correlation with the $A R_{\mathrm{e}}$ for $\mathrm{TC}$ adsorption. Moderate correlations between $q_{\mathrm{m}}$ and $\mathrm{pH}$, and between $A R_{\mathrm{e}}$ and $S_{\mathrm{BET}}$ were observed in $\mathrm{Cu}^{2+}$ adsorption $(r>0.5)$; and the other indexes maintained a low degree of correlation. $q_{\mathrm{m}}$ and $\mathrm{S}_{\mathrm{BET}}$ in TC adsorption were moderately correlated, and the other indexes maintained a low degree of correlation. The results indicate that the $\mathrm{pH}$ and $\mathrm{S}_{\mathrm{BET}}$ of the material have a greater influence on $\mathrm{Cu}^{2+}$ and $\mathrm{TC}$ adsorptions respectively, than CEC.

\section{Adsorption difference of $\mathrm{Cu}^{2+}$ and TC on BS-B/MBC}

Figure 9 shows the adsorption difference of $\mathrm{Cu}^{2+}$ and $\mathrm{TC}$ on $\mathrm{BS}-\mathrm{B} / \mathrm{MBC}$. The $\mathrm{S}_{\mathrm{BET}}$, pore structure, and functional groups of $\mathrm{BC}$ determined its adsorption capacity for $\mathrm{Cu}^{2+}$ and $\mathrm{TC}$, but the adsorption capacity of original BC was limited. Solid-liquid separation could be realized under the action of external magnetic field by magnetizing the material with the magnetic medium. $\mathrm{Fe}_{3} \mathrm{O}_{4}$ loading increased the $\mathrm{S}_{\mathrm{BET}}$ and effective adsorption sites on the surface of $\mathrm{BC} . \mathrm{MBC}$ and $\mathrm{BS}-\mathrm{B} / \mathrm{MBC}$ had good magnetic separation performances and could be separated by applying a magnetic field.

B had strong adsorption capacity and ion exchange capacity, and amphoteric modification could remarkably improve its adsorption capacity for heavy metals and organic pollutants (Li et al., 2016c). Therefore, BS-B had high adsorption capacity for $\mathrm{Cu}^{2+}$ and TC. When MBC was loaded with BS-B, BS- 
284

285

286

287

288

289

290

291

292

293

294

295

296

297

298

299

300

301

302

303

304

305

306

307

308

309

310

$\mathrm{B} / \mathrm{MBC}$ had a strong affinity for heavy metal ions and could effectively fix $\mathrm{Cu}^{2+}$, and which increases the adsorption capacity for $\mathrm{Cu}^{2+}$. The adsorption mechanism of $\mathrm{Cu}^{2+}$ comes from ion exchange, complexation, and electrostatic attraction by $\mathrm{BC}$ and from complexation and electrostatic attraction by BS-B (Zhang et al., 2020). TC has multiple ionizable functional groups, contains two groups of positive and negative charges, and has hydrophilicity (Khanday and Hameed, 2018). When the $\mathrm{pH}$ of the solution changed, the adsorption behavior of BS-B/MBC became more complicated. The relatively high surface area and large pore size of BS-B/MBC provided more active sites for TC molecules (Jang et al., 2018). The rapid adsorption stage dominated the adsorption process of TC. The adsorption mechanism of TC comes from ion exchange and hydrophobic combination by BC and from complexation and hydrophobic combination by BS-B (Zou al., 2020). Moreover, the FTIR spectra of 100BS-B/MBC before and after $\mathrm{Cu}^{2+}$ and TC adsorptions were compared (Fig. 10). The results showed that the $\mathrm{C}=\mathrm{O}$ and $\mathrm{C}-\mathrm{H}$ bonds on the surface of the material shifted after $\mathrm{Cu}^{2+}$ adsorption, which indicates that $\mathrm{C}=\mathrm{O}$ and $\mathrm{C}-\mathrm{H}$ on the surface of $100 \mathrm{BS}-\mathrm{B} / \mathrm{MBC}$ were involved in the $\mathrm{Cu}^{2+}$ and $\mathrm{TC}$ adsorption processes. The appearance of $\mathrm{O}-\mathrm{H}$ bonds on 100BS-B/MBC after TC adsorption showed that hydroxyl group participates in the TC adsorption process. Additionally, the movement of the peak to a higher wave number means that the energy required for vibration is lower, which indicates that the group is more stable.

\section{CONCLUSION}

After magnetization, $\mathrm{BC}$ had reduced $\mathrm{pH}$ and $\mathrm{CEC}$ and increased $\mathrm{S}_{\mathrm{BET}}$. BC had a smooth surface, but the surface smoothness of $\mathrm{BS}-\mathrm{B} / \mathrm{BC}$ increased with the increase in BS-12 modification on BS-B. After $\mathrm{Fe}_{3} \mathrm{O}_{4}$ was loaded, a large number of $\mathrm{Fe}_{3} \mathrm{O}_{4}$ particles adhered to the surface of BS-B/MBC, and its surface became rough. Compared with unmagnetizatic ones, the magnetized materials had higher weight loss rates. FTIR and VSM analyses proved that $\mathrm{BS}-12$ and $\mathrm{Fe}_{3} \mathrm{O}_{4}$ were modified to the surface of $\mathrm{BS}-\mathrm{B} / \mathrm{MBC}$. $\mathrm{MBC}$ and $\mathrm{BS}-\mathrm{B} / \mathrm{MC}$ had good magnetic separation performances. BS-B/MBC had a good adsorption effects on $\mathrm{Cu}^{2+}$ and $\mathrm{TC}$, and its $A R_{\mathrm{e}}$ was more than $80 \% . \mathrm{Cu}^{2+}$ and $\mathrm{TC}$ adsorptions were spontaneous, endothermic, and entropy-adding reactions. The $\mathrm{pH}$ and $\mathrm{S}_{\mathrm{BET}}$ of the material had a great influence on $\mathrm{Cu}^{2+}$ and $\mathrm{TC}$ adsorptions, respectively.

\section{ACKNOWLEDGEMENTS}

The authors wish to acknowledge and thank the Fundamental Research Funds of China West Normal University (18B023), the Tianfu Scholar Program of Sichuan Province (2020-17), the Sichuan Province 
311 Science and Technology Support Program (2018JY0224) and the National Natural Science Foundation of 312 China (41271244).

\section{CONFLICT OF INTRESTS}

314 The authors declare that they have no conflict of interest.

315

316

317

318

319

320

321

322

323

324

325

326

327

328

329

330

331

332

333

\section{REFERENCES}

Ahmad M, Rajapaksha A U, Lim J E, Ming Z, Bolan N, Mohan D, Vithanage M, Sang SL, Yong SO. 2014. Biochar as a sorbent for contaminant management in soil and water: A review. Chemosphere 99(1):19-33 DOI 10.1016/j.chemosphere.2013.10.071

Ana FV, Sérgio VPB, Ana C, Anabela C, Beatriz P. 2013. Influence of the storage conditions on the physicochemical properties, antioxidant activity and microbial flora of different tomato (lycopersicon esculentum l.) cultivars. Journal of Agricultural Science 5(2):118-128 DOI 10.5539/jas.v5n2p118

Beraa A, Hajjaji M, Laurent R, Delavaux-Nicot B, Caminade AM. 2016. Removal of chromate from aqueous solutions by dendrimers-clay nanocomposites. Desalination and Water Treatment 57(30): 1429014303 DOI 10.1080/19443994.2015.1062429

Feng LR, jiao L, Yuan GD, Bi DX, Wei j. 2020. Biomass feedstocks and carbonization methods affect antibiotic adsorption on biochar. China Environmental Science 40(3):1156-1165 DOI 10.19674/j.cnki.issn1000-6923.2020.0078 [in chinese]

Fu JG, Jia Y, Li Z, Huang YT, Wang XB, Zhao D. 2019. Preparation of Mg-Fe hydrotalcite supported on magnetic biochar and its adsorption capacity to $\mathrm{Cd}(\mathrm{I})$ and $\mathrm{Ni}(\mathrm{I})$ from water. Environmental Protection of Chemical Industry 39(5):574-580 DOI 10.3969/j.issn.1006-1878.2019.05.015 [in chinese]

Garg R, Garg R, Thakur A, Arif SM. 2021. Water remediation using biosorbent obtained from agricultural and fruit waste. Materials Today: Proceedings 46(15):6669-6672 DOI 10.1016/j.matpr.2021.04.132

He HX, Li WB, Deng HY, Ren LP, Li T. 2019. Surface characteristics of a recyclable and efficient adsorption material. Materials Letters 256:126658-126658 DOI 10.1016/j.matlet.2019.126658

Isakovski MK, Beljin J, Trikovi J, Ronevi S, Maleti S. 2020. Current state and future perspectives of carbon based materials in the environment: fate and application. Recent Patents on Nanotechnology 15(3):183-196 DOI 10.2174/1872210514666201217150323

Jang HM, Yoo S, Choi YK, Park S, Kan E. 2018. Adsorption isotherm, kinetic modeling and mechanism of tetracycline on pinus taeda-derived activated biochar. Bioresource Technology, 259:24-31 DOI 10.1016/j.biortech.2018.03.013

Kastner JR, Mani S, Juneja A. 2015. Catalytic decomposition of tar using iron supported biochar. Fuel Processing Technology 130:31-37 DOI 10.1016/j.fuproc.2014.09.038 
Khan F, Khan MJ, Samad A, Noor Y, Rashid M, Jan B. 2015. In-situ stabilization of heavy metals in agriculture soils irrigated with untreated wastewater. Journal of Geochemical Exploration. 159:1-7 DOI 10.1016/j.gexplo.2015.07.002

Khanday WA, Hameed BH. 2018. Zeolite-hydroxyapatite-activated oil palm ash composite for antibiotic tetracycline adsorption. Fuel 215(3):499-505 DOI 10.1016/j.fuel.2017.11.068

Kumar L, Ragunathan V, Chugh M, Bharadvaja N. 2021. Nanomaterials for remediation of contaminants: a review. Environmental Chemistry Letters, 19(6):3139-3163 DOI 10.1007/s10311-021-01212-z

Kyung-Won J, Brian HC, Tae-Un J, Kyu-Hong A. 2016. Facile synthesis of magnetic biochar $/ \mathrm{Fe}_{3} \mathrm{O}_{4}$ nanocomposites using electro-magnetization technique and its application on the removal of acid orange 7 from aqueous media. Bioresource Technology 220:672-676 DOI 10.1016/j.biortech.2016.09.035

Lawal AA, Hassan MA, Farid M, Yasim-Anuar T, Shirai Y. 2021. Adsorption mechanism and effectiveness of phenol and tannic acid removal by biochar produced from oil palm frond using steam pyrolysis. Environmental Pollution 269(15):116197-116208 DOI 10.1016/j.envpol.2020.116197

Li G, Zhu W, Zhang C, Shen Z, Zhao W. 2016a. Effect of a magnetic field on the adsorptive removal of methylene blue onto wheat straw biochar. Bioresource Technology 206:16-22 DOI 10.1016/j.biortech.2015.12.087

Li WB, Meng ZF, Liu Z, Chen HY, Wu Q, Xu SE. 2016b. Chromium (VI) adsorption characteristics of bentonite under different modification patterns. Polish Journal of Environmental Studies 25(3):1075-1083 DOI 10.15244/pjoes/61626

Li WB, Liu Z, Meng ZF, Ren S, Xu SE, Zhang Y, Wang MY. 2016c. Composite modification mechanism of cationic modifier to amphoteric modified kaolin and its effects on surface characteristics. International Journal of Environmental Science and Technology 13(11): 2639-2648 DOI 10.1007/s13762-016-1091-3

Li WB, He HX, Kang L, Yang DQ, Zhuang Q, Meng ZF, Li XL, Li YX. 2020. Restoration of $\mathrm{Cu}^{2+}$ contaminated purple soil by applying yeasract and interplant. Applied Ecology and Environmental Research 18(5):6623-6635 DOI 10.15666/aeer/1805_66236635

Lopez J, Boyd D, Ylitalo GM, Littnan C, Pearce R. 2012. Persistent organic pollutants in the endangered hawaiian monk seal (monachus schauinslandi) from the main hawaiian islands. Marine Pollution Bulletin 64(11):2588-2598 DOI 10.1016/j.marpolbul.2012.07.012

Mazurkiewicz J, Mazur A, Mazur R, Chmielowski K, Janczak D. 2020. The process of microbiological remediation of the polluted soneczko reservoir in poland: for reduction of water pollution and nutrients management. Water 12(11):3002-3011 DOI 110.3390/w12113002

Meng ZF, Zhang YP, Wang GD. 2007. Sorption of heavy metal and organic pollutants on modified soils. Pedosphere 17(2): 235-245 DOI 10.1016/S1002-0160(07)60030-7

Min Z, Liu YS, Zhao JL, Liu WR, He LY, Zhang JN, Chen J, He LK, Zhang QQ, Ying GG. 2018. Occurrence, fate and mass loadings of antibiotics in two swine wastewater treatment systems. Science of the Total Environment 639:1421-1431 DOI 10.1016/j.scitotenv.2018.05.230 
Mohan D, Sarswat A, Ok YS, Pittman CU. 2014. Organic and inorganic contaminants removal from water with biochar, a renewable, low cost and sustainable adsorbent: A critical review. Bioresource Technology 160(1):191-202 DOI 10.1016/j.biortech.2014.01.120

Nyamukamba P, Moloto MJ, Tavengwa N, Ejidike, IP. 2019. Evaluating physicochemical parameters, heavy metals, and antibiotics in the influents and final effluents of south african wastewater treatment plants. Polish Journal of Environmental Studies 28(3):1305-1312 DOI 10.15244/pjoes/85122

Park JH, Ok YS, Kim SH, Cho JS, Heo JS, Delaune RD, Dong-Cheol S. 2016. Competitive adsorption of heavy metals onto sesame straw biochar in aqueous solutions. Chemosphere 142(1):77-83 DOI 10.1016/j.chemosphere.2015.05.093

Said AEA, Goda, MN. 2021. Superior competitive adsorption capacity of natural bentonite in the efficient removal of basic dyes from aqueous solutions. Chemistry Select 6(11):2790-2803 DOI $10.1002 /$ slct.202100575

Shah LA, Silva-Valenzuela MDGD, Farooq M, Khattak, SA, Diaz V, Rolando F. 2018. Influence of preparation methods on textural properties of purified bentonite. Applied Clay Science, 162(9):155-164 DOI 10.1016/j.clay.2018.06.001

Wang B, Li Y, Zheng J, Hu Y, Wang X, Hu B. 2020. Efficient removal of U(VI) from aqueous solutions using the magnetic biochar derived from the biomass of a bloom-forming cyanobacterium (microcystis aeruginosa). Chemosphere 254:126898-126909 DOI 10.1016/j.chemosphere.2020.126898

Xin O, Han Y, Xi C, Chen J. 2017. Magnetic biochar combining adsorption and separation recycle for removal of chromium in aqueous solution. Water Science \& Technology 75(5):1177-1184 DOI 10.2166/wst.2016.610

Yan J, Han L, Gao W, Xue S, Chen M. 2015. Biochar supported nanoscale zerovalent iron composite used as persulfate activator for removing trichloroethylene. Bioresource Technology, 175:269-274 DOI 10.1016/j.biortech.2014.10.103

Yang X, Liu J J, Mcgrouther K, Huang HG, Lu KP, Guo X, He LZ, Lin XM, Che L, Ye ZQ, Wang HL. 2016. Effect of biochar on the extractability of heavy metals $(\mathrm{Cd}, \mathrm{Cu}, \mathrm{Pb}$, and $\mathrm{Zn})$ and enzyme activity in soil. Environmental Science and Pollution Research 23(2):974-984 DOI 10.1007/s11356-015-4233-0

Zhao YH, Li WB, Yi HY, Liang Q, Dong ZM, Deng HY. 2021. Adsorption and desorption mechanisms of $\mathrm{Cu}^{2+}$ on amended subsurface riverbank soils. Desalination and Water Treatment 221(5): 252-259 DOI $10.5004 /$ dwt.2021.27045

Zhang YF, Deng HY, Zhu L, Xie J, Kang L, Li WB, Liu W, Meng ZF. 2020. Difference of adding different compositely modified amphipathic maifanite on $\mathrm{Cu}^{2+}$ adsorption. Desalination and Water Treatment 178(2): 203-210 DOI 10.5004/dwt.2020.24968

Zou Y, Deng HY, Li M, Zhao YH, Li WB. 2020. Enhancing tetracycline adsorption by riverbank soils by application of biochar-based composite materials. Desalination and Water Treatment 207(2):332-340 DOI $10.5004 /$ dwt.2020.26392 
415 Zulfiqar M, Sufian S, Bahadar A, Lashari N, Mansor N. 2021. Surface-fluorination of $\mathrm{TiO}_{2}$ photocatalysts 416 for remediation of water pollution: a review. Journal of Cleaner Production 317(5): 128354-128365 DOI $417 \quad 10.1016 /$ j.jclepro.2021.128354 


\section{Table $\mathbf{1}$ (on next page)}

TG (\%) and DTG (\%/min) curves of the test materials

$\mathrm{BC}$ and $\mathrm{MBC}$ stand for original biochar and magnetic biochar, respectively. B/BC, 50BS-B/BC, and 50BS-B/BC were $0 \%, 50 \%$, and 100\% BS-12 modified bentonite loaded BC. B/MBC, 50BS-B/MBC, and 50BS-B/MBC represent $0 \%, 50 \%$, and $100 \%$ BS-12 modified bentonite loaded MBC. The same as other tables. 


\begin{tabular}{|c|c|c|c|c|c|c|}
\hline \multirow{2}{*}{ Treatments } & \multicolumn{2}{|c|}{$\begin{array}{c}\text { Dehydration } \\
\text { Stage } 1\left(<250{ }^{\circ} \mathrm{C}\right)\end{array}$} & \multicolumn{2}{|c|}{$\begin{array}{c}\begin{array}{c}\text { Organic carbon } \\
\text { decomposition }\end{array} \\
\text { Stage } 2\left(250 \sim 600{ }^{\circ} \mathrm{C}\right)\end{array}$} & \multirow{2}{*}{$\begin{array}{c}\begin{array}{c}\text { Crystal layer } \\
\text { collapse } \\
\text { Stage } 3(>600 \\
\left.{ }^{\circ} \mathrm{C}\right)\end{array} \\
\text { Peak } \\
\text { temperature }\left({ }^{\circ} \mathrm{C}\right) \\
\end{array}$} & \multirow{2}{*}{$\begin{array}{r}\text { Residual } \\
\text { rate }(\%)\end{array}$} \\
\hline & $\begin{array}{c}\text { Water loss } \\
\text { rate }(\%)\end{array}$ & $\begin{array}{c}\text { Peak } \\
\text { temperature }\left({ }^{\circ} \mathrm{C}\right)\end{array}$ & $\begin{array}{c}\text { Carbon loss } \\
\text { rate (\%) }\end{array}$ & $\begin{array}{c}\text { Peak } \\
\text { temperature }\left({ }^{\circ} \mathrm{C}\right)\end{array}$ & & \\
\hline $\mathrm{BC}$ & 6.68 & 67.13 & 11.6 & 403.49 & 618.98 & 65.71 \\
\hline $\mathrm{B} / \mathrm{BC}$ & 8.07 & 68.34 & 15.1 & 444.69 & 633.35 & 68.61 \\
\hline 50BS-B/BC & 7.51 & 69.51 & 18.04 & 481.68 & 692.78 & 67.28 \\
\hline 100BS-B/BC & 8.26 & 67.25 & 23.48 & 525.85 & 750.44 & 66.63 \\
\hline $\mathrm{MBC}$ & 4.59 & 68.16 & 15.96 & 436.72 & 640.11 & 75.19 \\
\hline $\mathrm{B} / \mathrm{MBC}$ & 4.17 & 79.82 & 19.2 & 448.31 & 651.61 & 72.01 \\
\hline 50BS-B/MBC & 4.74 & 80.67 & 20.07 & 451.87 & 652.43 & 71.18 \\
\hline 100BS-B/MBC & 5.02 & 70.48 & 21.17 & 455.23 & 642.39 & 70.24 \\
\hline
\end{tabular}

1 


\section{Table 2 (on next page)}

Langmuir fitting parameters and thermodynamic parameters for $\mathrm{Cu}^{2+}$ adsorption

** indicates that the correlation coefficient is significant at $p=0.01$ level ( $r=0.798$ when the degree of freedom $f=7$ and the level of significance $p=0.01$ ). 


\begin{tabular}{|c|c|c|c|c|c|c|c|c|c|}
\hline \multirow{2}{*}{ Treatments } & \multicolumn{4}{|c|}{ Fitting parameters } & \multirow{2}{*}{$\begin{array}{c}\text { Average } \\
\text { adsorptio } \\
\text { n rate } \\
(\%)\end{array}$} & \multicolumn{4}{|c|}{ Thermodynamic parameters } \\
\hline & $\begin{array}{l}\text { Correlation } \\
\text { coefficient } / r\end{array}$ & $\begin{array}{c}\text { Standard } \\
\text { deviation/ } \\
S\end{array}$ & $\begin{array}{c}q_{m} \\
(\mathrm{mmol} / \mathrm{kg} \\
)\end{array}$ & $\boldsymbol{b}$ & & $\begin{array}{c}\Delta G_{20} \\
(\mathrm{~kJ} / \mathrm{mol} \\
)\end{array}$ & $\begin{array}{c}\Delta G_{40} \\
(\mathrm{~kJ} / \mathrm{mol} \\
)\end{array}$ & $\begin{array}{c}\Delta H \\
(\mathrm{~kJ} / \mathrm{mol} \\
)\end{array}$ & $\begin{array}{c}\Delta S \\
(\mathrm{~J} / \mathrm{mol} / \mathrm{K} \\
)\end{array}$ \\
\hline $\mathrm{BC}$ & $0.9923^{* *}$ & 5.70 & 135.07 & $\begin{array}{c}1.1 \\
6\end{array}$ & 62.87 & -17.13 & -18.62 & 4.76 & 74.68 \\
\hline $\mathrm{B} / \mathrm{BC}$ & $0.9948^{* *}$ & 7.78 & 199.80 & $\begin{array}{c}4.2 \\
2\end{array}$ & 84.42 & -20.25 & -21.84 & 3.07 & 79.55 \\
\hline $50 \mathrm{BS}-\mathrm{B} / \mathrm{BC}$ & $0.9905^{* *}$ & 12.02 & 240.43 & $\begin{array}{c}4.1 \\
0\end{array}$ & 88.21 & -20.15 & -21.77 & 3.49 & 80.67 \\
\hline 100BS-B/BC & $0.9897^{* *}$ & 13.59 & 286.31 & $\begin{array}{c}3.3 \\
2\end{array}$ & 90.08 & -19.70 & -21.22 & 2.64 & 76.21 \\
\hline $\mathrm{MBC}$ & $0.9949^{* *}$ & 5.20 & 157.18 & $\begin{array}{c}1.0 \\
6\end{array}$ & 66.29 & -16.75 & -18.43 & 7.89 & 84.03 \\
\hline $\mathrm{B} / \mathrm{MBC}$ & $0.9978^{* *}$ & 5.60 & 234.77 & $\begin{array}{c}3.6 \\
7\end{array}$ & 87.31 & -19.76 & -21.57 & 6.72 & 90.33 \\
\hline 50BS-B/MBC & $0.9954^{* *}$ & 8.89 & 264.49 & $\begin{array}{c}3.9 \\
2\end{array}$ & 89.93 & -20.04 & -21.61 & 3.00 & 78.60 \\
\hline $\begin{array}{l}\text { 100BS- } \\
\text { B/MBC }\end{array}$ & $0.9968^{* *}$ & 8.03 & 322.00 & $\begin{array}{c}3.1 \\
5\end{array}$ & 91.92 & -19.52 & -21.07 & 3.23 & 77.61 \\
\hline
\end{tabular}




\section{Table 3(on next page)}

Langmuir fitting parameters and thermodynamic parameters for TC adsorption

** indicates that the correlation coefficient is significant at $p=0.01$ level ( $r=0.798$ when the degree of freedom $f=7$ and the level of significance $p=0.01$ ). 


\begin{tabular}{|c|c|c|c|c|c|c|c|c|c|}
\hline \multirow{2}{*}{ Treatments } & \multicolumn{4}{|c|}{ Fitting parameters } & \multirow{2}{*}{$\begin{array}{c}\text { Average } \\
\text { adsorptio } \\
\text { n rate } \\
(\%)\end{array}$} & \multicolumn{4}{|c|}{ Thermodynamic parameters } \\
\hline & $\begin{array}{l}\text { Correlation } \\
\text { coefficient } / r\end{array}$ & $\begin{array}{c}\text { Standard } \\
\text { deviation/ } \\
S \\
\end{array}$ & $\begin{array}{c}q_{m} \\
(\mathbf{m m o l} / \mathbf{k} \\
\mathrm{g})\end{array}$ & $\boldsymbol{b}$ & & $\begin{array}{c}\Delta G_{20} \\
(\mathrm{~kJ} / \mathrm{mol} \\
)\end{array}$ & $\begin{array}{c}\Delta G_{40} \\
(\mathrm{~kJ} / \mathrm{mol} \\
)\end{array}$ & $\begin{array}{c}\Delta H \\
(\mathrm{~kJ} / \mathrm{mol} \\
)\end{array}$ & $\begin{array}{c}\Delta S \\
(\mathrm{~J} / \mathrm{mol} / \mathrm{K} \\
)\end{array}$ \\
\hline $\mathrm{BC}$ & $0.9964^{* *}$ & 0.70 & 336.59 & 3.53 & 89.54 & -19.96 & -21.34 & 0.41 & 69.47 \\
\hline $\mathrm{B} / \mathrm{BC}$ & $0.9975^{* *}$ & 0.58 & 152.82 & 10.20 & 92.72 & -22.49 & -24.09 & 0.86 & 79.66 \\
\hline 50BS-B/BC & $0.9977^{* *}$ & 0.56 & 118.60 & 14.30 & 93.83 & -23.31 & -24.96 & 0.92 & 82.63 \\
\hline 100BS-B/BC & $0.9971^{* *}$ & 0.62 & 155.11 & 9.16 & 92.20 & -22.23 & -23.82 & 0.97 & 79.15 \\
\hline MBC & $0.9945^{* *}$ & 0.92 & 501.00 & 7.23 & 96.31 & -21.67 & -23.17 & 0.39 & 75.26 \\
\hline $\mathrm{B} / \mathrm{MBC}$ & $0.9919^{* *}$ & 1.10 & 602.83 & 7.82 & 96.77 & -21.81 & -23.35 & 0.76 & 76.98 \\
\hline 50BS-B/MBC & $0.9955^{* *}$ & 0.83 & 432.28 & 13.91 & 97.76 & -23.24 & -24.85 & 0.36 & 80.52 \\
\hline $\begin{array}{l}\text { 100BS- } \\
\text { B/MBC }\end{array}$ & $0.9953^{* *}$ & 0.84 & 425.92 & 12.32 & 97.60 & -22.91 & -24.57 & 1.20 & 82.27 \\
\hline
\end{tabular}




\section{Table 4(on next page)}

Correlation s between $\mathrm{Cu}^{2+}(\mathrm{TC})$ adsorption and physicochemical properties

$q_{\mathrm{m}}$ and $A R_{e}$ were maximum adsorption amount and average adsorption rate of $\mathrm{Cu}^{2+}(\mathrm{TC})$ respectively. 


\begin{tabular}{|c|c|c|c|c|c|}
\hline \multicolumn{2}{|c|}{$\begin{array}{l}\text { Adsorption } \\
\text { parameters }\end{array}$} & $\begin{array}{c}\text { physicochemical } \\
\text { properties }\end{array}$ & Regression equation & $\begin{array}{l}\text { Correlation } \\
\text { coefficients } / r\end{array}$ & $\begin{array}{c}\text { Standard } \\
\text { deviation } / S\end{array}$ \\
\hline \multirow{6}{*}{$\mathrm{Cu}^{2+}$} & \multirow{3}{*}{$q_{\mathrm{m}}$} & $\mathrm{pH}$ & $\mathrm{pH}=-0.01 q_{\mathrm{m}}+10.01$ & 0.6039 & 0.44 \\
\hline & & CEC & $\mathrm{CEC}=0.09 q_{\mathrm{m}}+189.36$ & 0.0642 & 80.79 \\
\hline & & $\mathrm{S}_{\mathrm{BET}}$ & $\mathrm{S}_{\mathrm{BET}}=-0.06 q_{\mathrm{m}}+22.38$ & 0.4696 & 5.74 \\
\hline & \multirow{3}{*}{$A R_{\mathrm{e}}$} & $\mathrm{pH}$ & $\mathrm{pH}=-2.22 E+10.62$ & 0.4895 & 0.49 \\
\hline & & CEC & $\mathrm{CEC}=130.21 E+100.80$ & 0.1980 & 79.36 \\
\hline & & $\mathrm{S}_{\mathrm{BET}}$ & $\mathrm{S}_{\mathrm{BET}}=-27.25 E+33.72$ & 0.5156 & 5.57 \\
\hline \multirow{6}{*}{$\mathrm{TC}$} & \multirow{3}{*}{$q_{\mathrm{m}}$} & $\mathrm{pH}$ & $\mathrm{pH}=0.27 q_{\mathrm{m}}+14.55$ & 0.2989 & 0.53 \\
\hline & & CEC & $\mathrm{CEC}=6.02 q_{\mathrm{m}}+79.86$ & 0.0459 & 80.87 \\
\hline & & $\mathrm{S}_{\mathrm{BET}}$ & $\mathrm{S}_{\mathrm{BET}}=6.65 q_{\mathrm{m}}-130.72$ & 0.6302 & 5.05 \\
\hline & \multirow{3}{*}{$A R_{\mathrm{e}}$} & $\mathrm{pH}$ & $\mathrm{pH}=-7.34 E+15.73$ & 0.4238 & 0.50 \\
\hline & & CEC & $\mathrm{CEC}=56.66 E+154.80$ & 0.0225 & 80.94 \\
\hline & & $\mathrm{S}_{\mathrm{BET}}$ & $\mathrm{S}_{\mathrm{BET}}=96.72 E-80.28$ & 0.4785 & 5.71 \\
\hline
\end{tabular}

1 
Figure 1

Structural formulas of BS-12 (A) and TC (B)

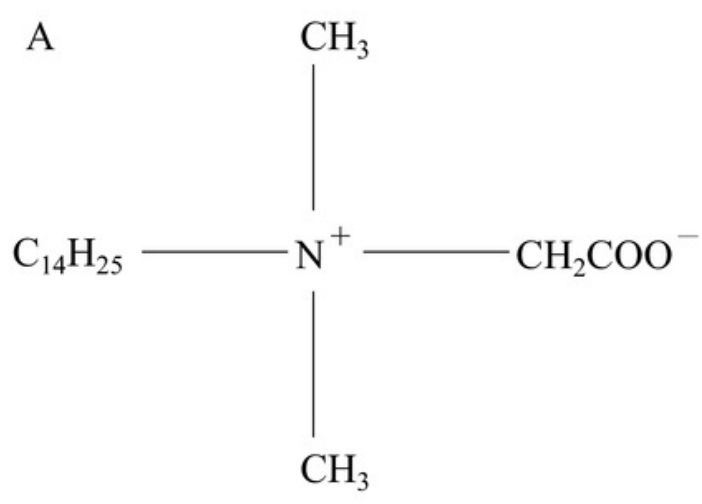

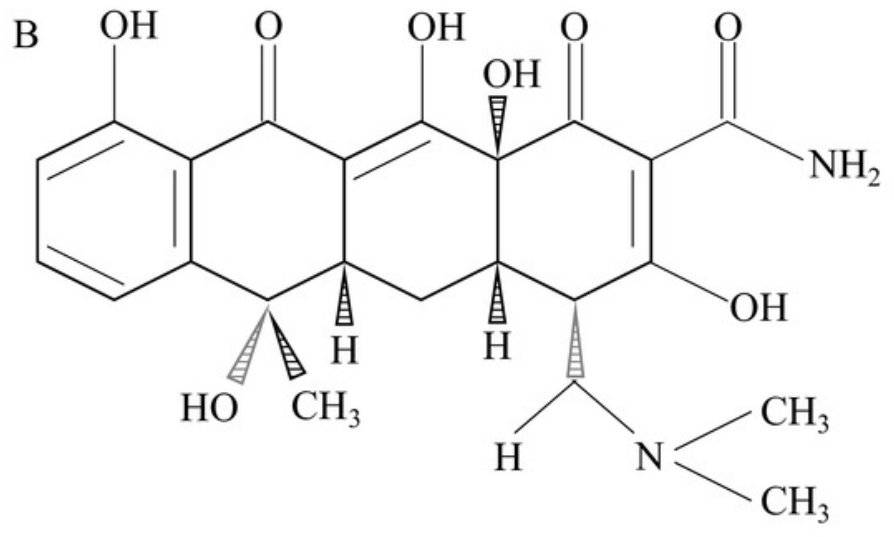




\section{Figure 2}

Physical and chemical characteristics of the test materials

Fig. $2 \mathrm{~A}-2 \mathrm{C}$ represent $\mathrm{pH}, \mathrm{CEC}$, and specific surface area respectively. $\mathrm{BC}$ and $\mathrm{MBC}$ stand for original biochar and magnetic biochar, respectively. $\mathrm{B} / \mathrm{BC}, 50 \mathrm{BS}-\mathrm{B} / \mathrm{BC}$, and $50 \mathrm{BS}-\mathrm{B} / \mathrm{BC}$ were $0 \%, 50 \%$, and $100 \% \mathrm{BS}-12$

modified bentonite loaded BC. B/MBC, 50BS-B/MBC, and 50BS-B/MBC represent $0 \%, 50 \%$, and $100 \% \mathrm{BS}-12$ modified bentonite loaded M BC. The same as other figures. The different uppercase and lowercase letters indicate significant difference among treatments at $p=0.01$ and $p=0.05$ level, respectively .

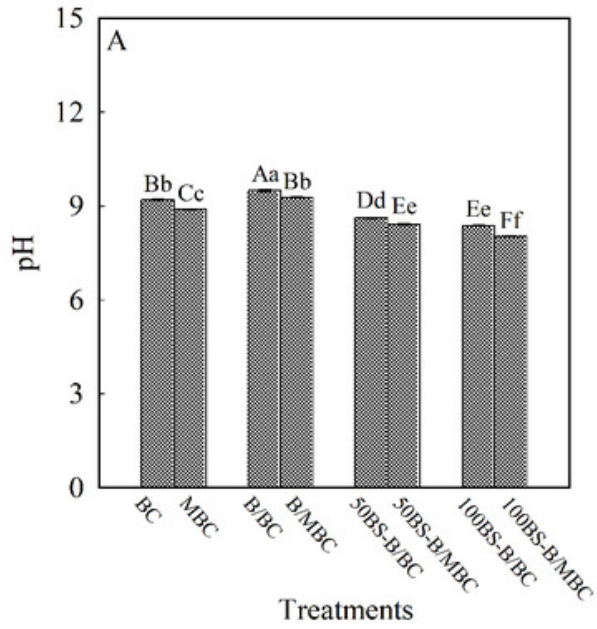

Treatments

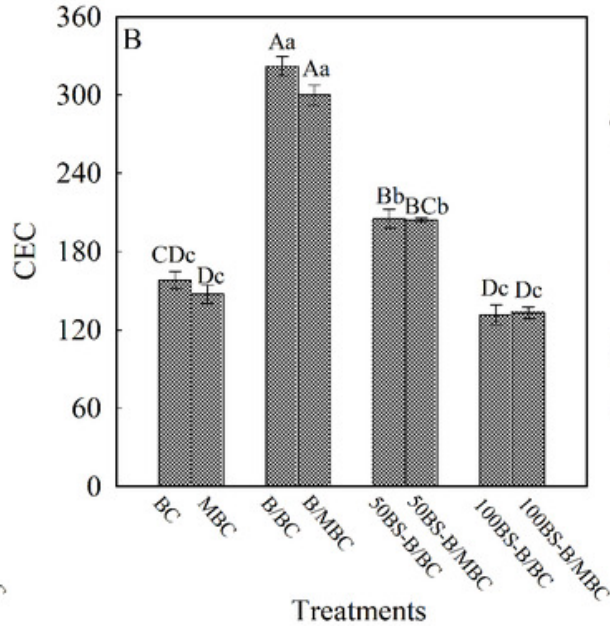

Treatments

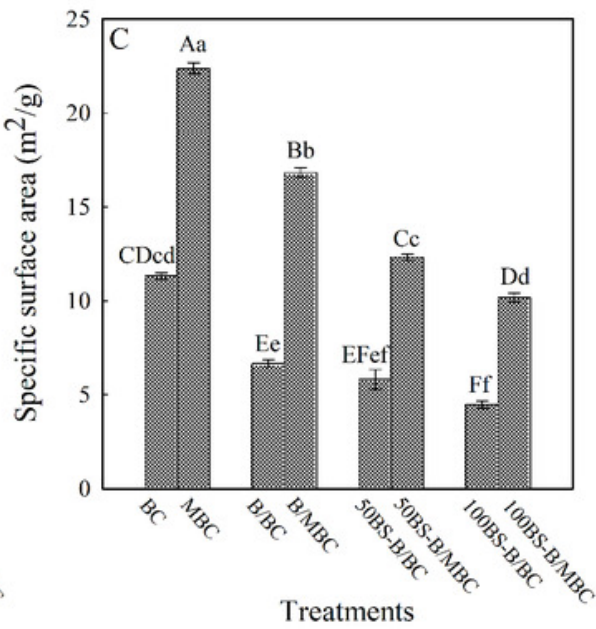

Treatments 
Figure 3

SEM images of test materials

Fig. $3 \mathrm{~A}$ - $3 \mathrm{~F}$ were $\mathrm{BC}, \mathrm{B} / \mathrm{BC}, 100 \mathrm{BS}-\mathrm{B} / \mathrm{BC}, \mathrm{MBC}, \mathrm{B} / \mathrm{MBC}$, and 100BS-B/MBC respectively.

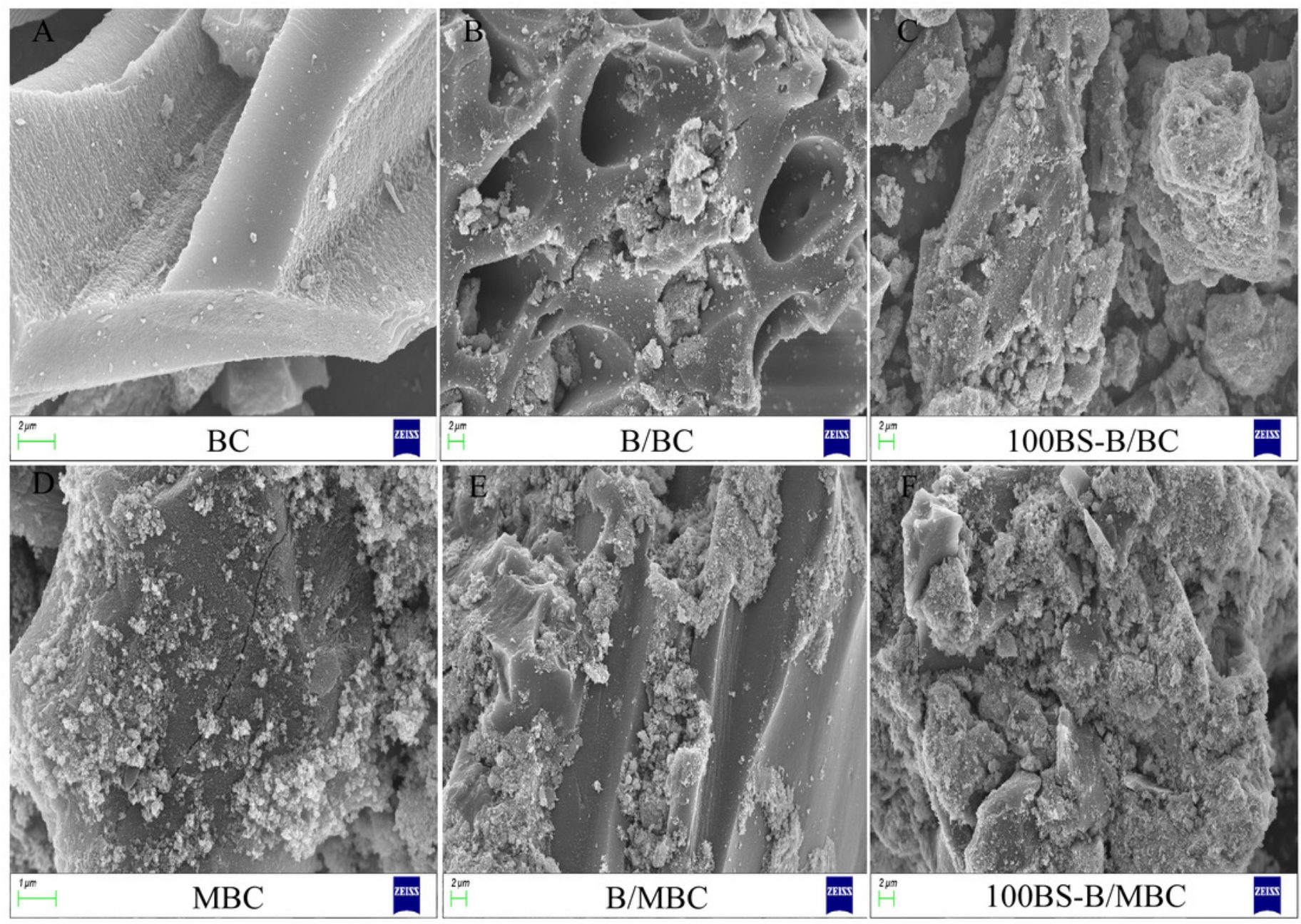


Figure 4

TG curves of test materials

Fig. $4 \mathrm{~A}$ and Fig. 4B were unmagnetized and magnetized materials respectively.
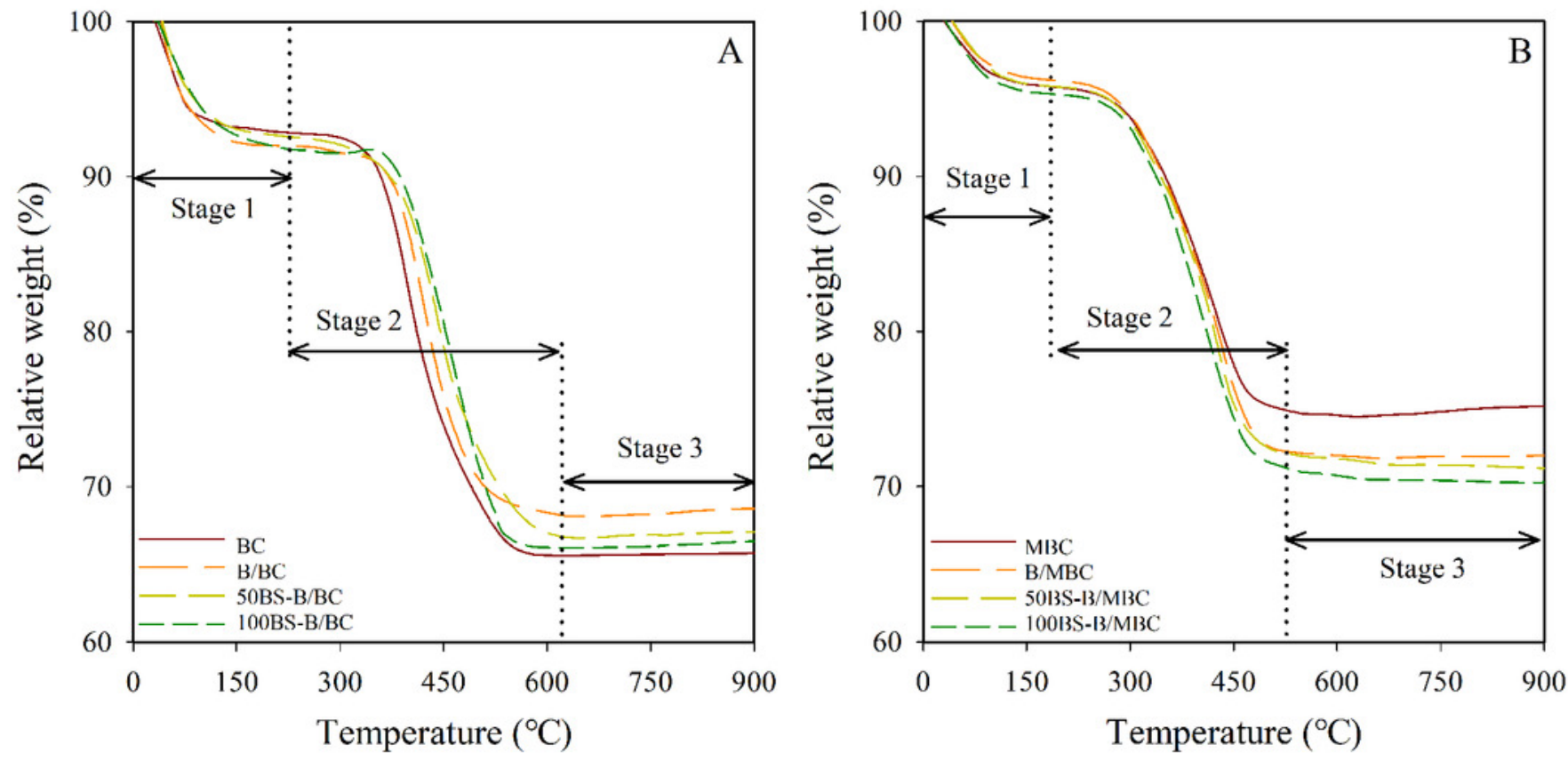
Figure 5

$2 \mathrm{D}$ infrared spectra of the test materials

Fig. $5 \mathrm{~A}$ and Fig. 5B were synchronous and asynchronous correlation diagram respectively.
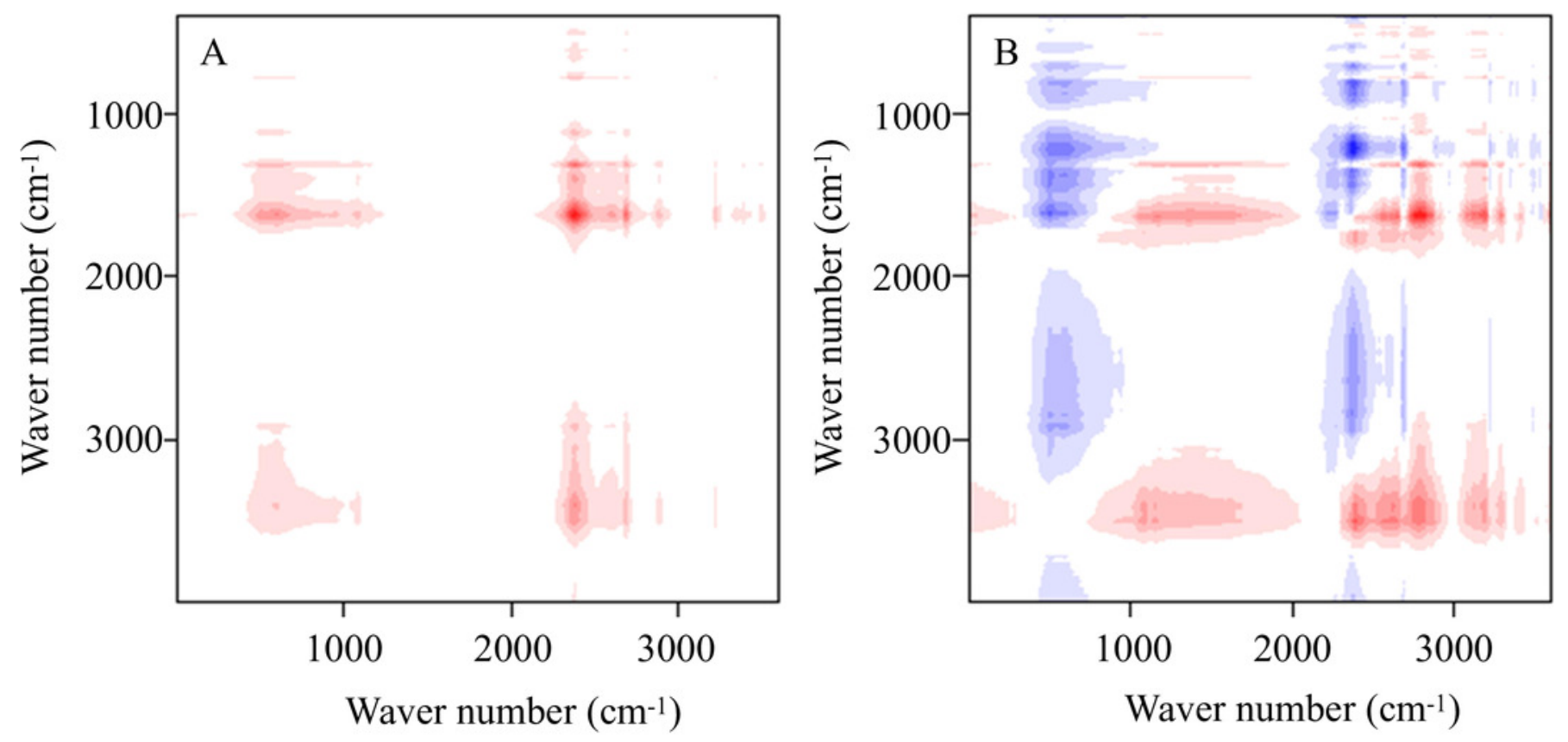
Figure 6

Hysteresis curves and magnetic effects of the test materials

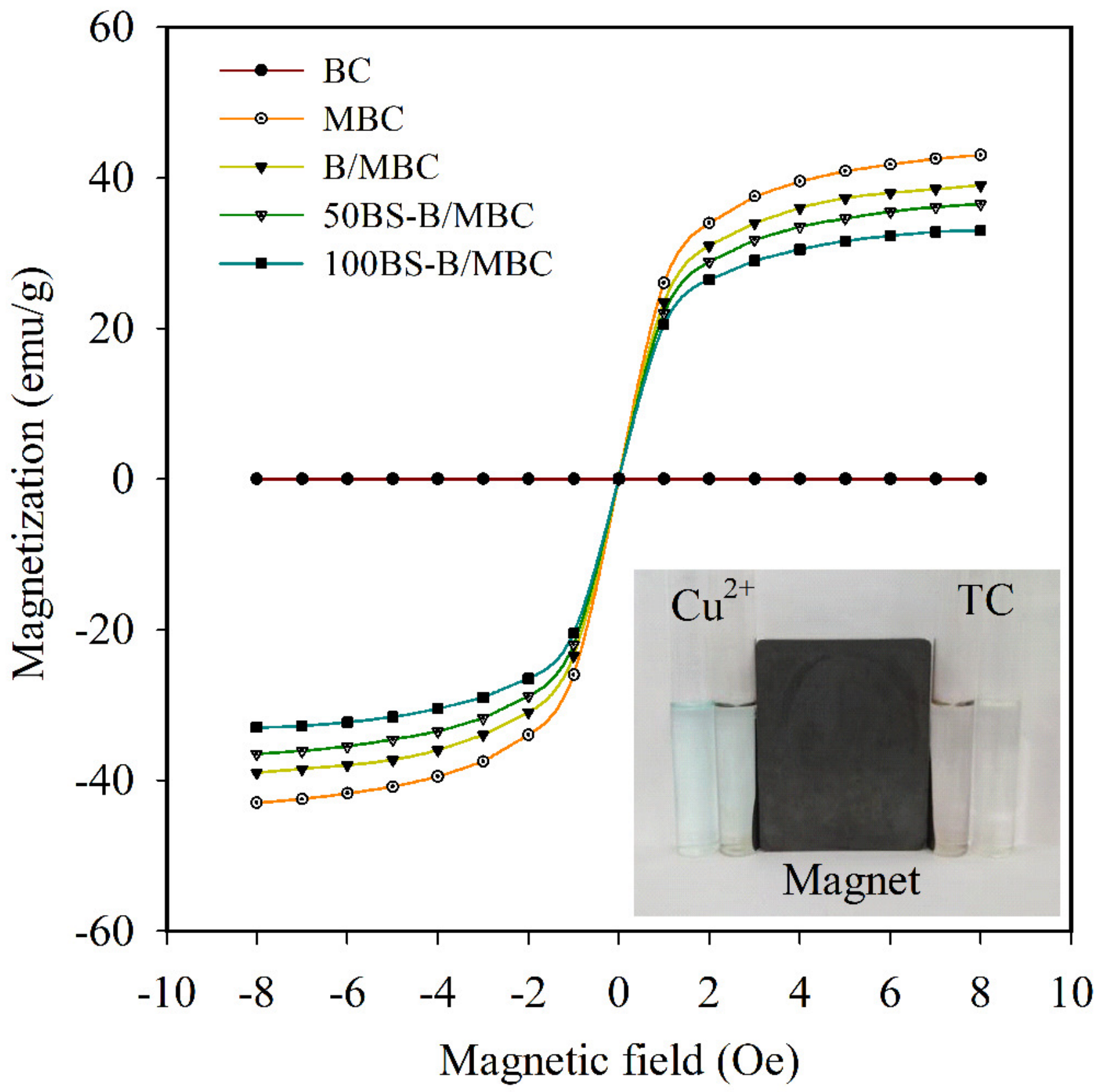


Figure 7

Adsorption isotherm and adsorption rate of $\mathrm{Cu}^{2+}$

Fig. 7A-7H were BC, B/BC, 50BS-B/BC, 100BS-B/BC, MBC, B/MBC, 50BS-B/MBC, and 100BS-B/MBC respectively.
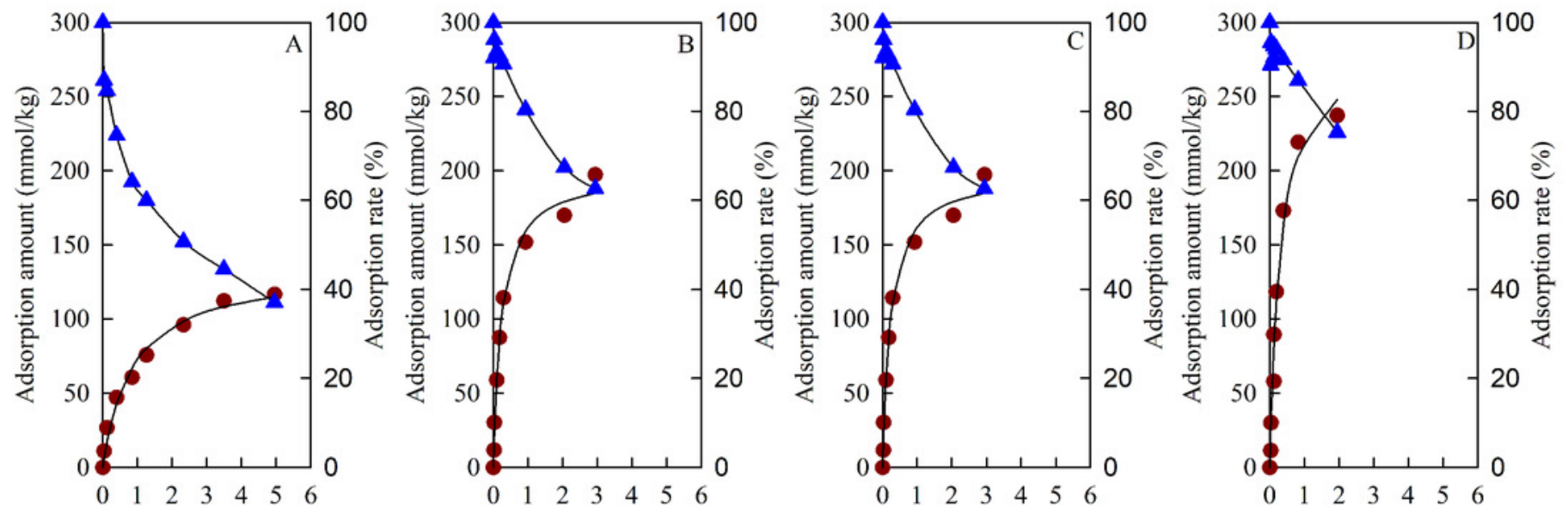

Equilibrum concentration (mmol/L) Equilibrum concentration (mmol/L) Equilibrum concentration (mmol/L) Equilibrum concentration (mmol/L)
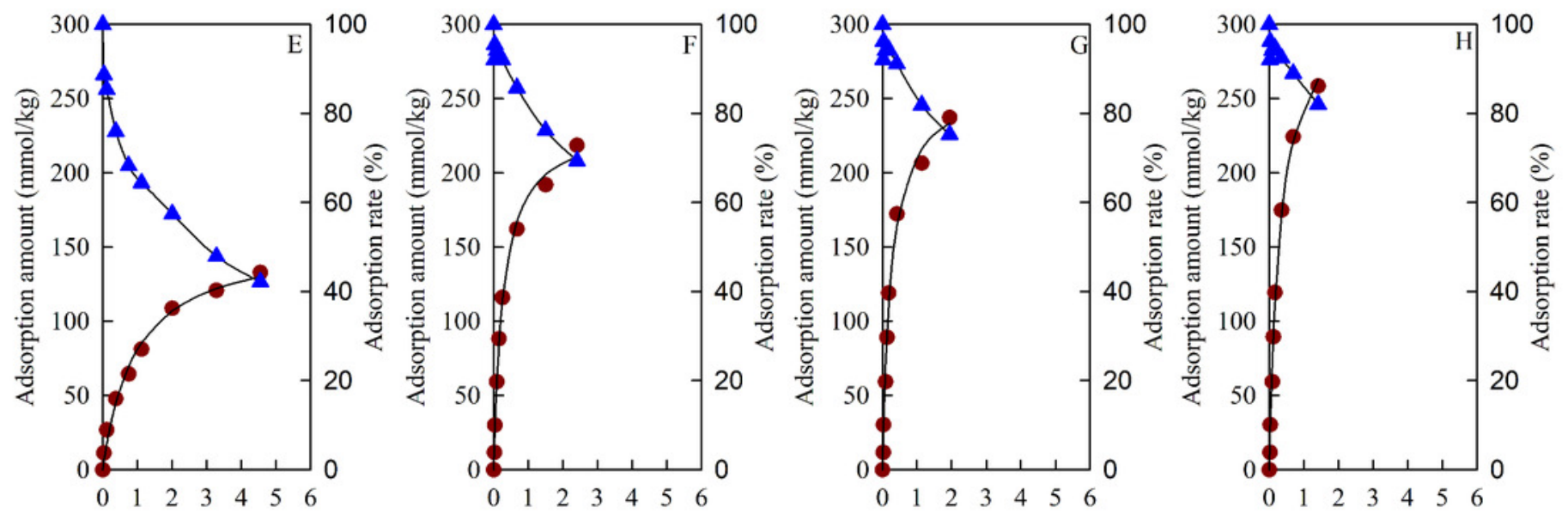

Equilibrum concentration $(\mathrm{mmol} / \mathrm{L})$ Equilibrum concentration $(\mathrm{mmol} / \mathrm{L})$ Equilibrum concentration $(\mathrm{mmol} / \mathrm{L})$ Equilibrum concentration $(\mathrm{mmol} / \mathrm{L})$

- Adsorption amount

$\Delta \quad$ Adsorption rate 
Figure 8

Adsorption isotherm and adsorption rate of TC

Fig. 7A-7H were BC, B/BC, 50BS-B/BC, 100BS-B/BC, MBC, B/MBC, 50BS-B/MBC, and 100BS-B/MBC respectively.
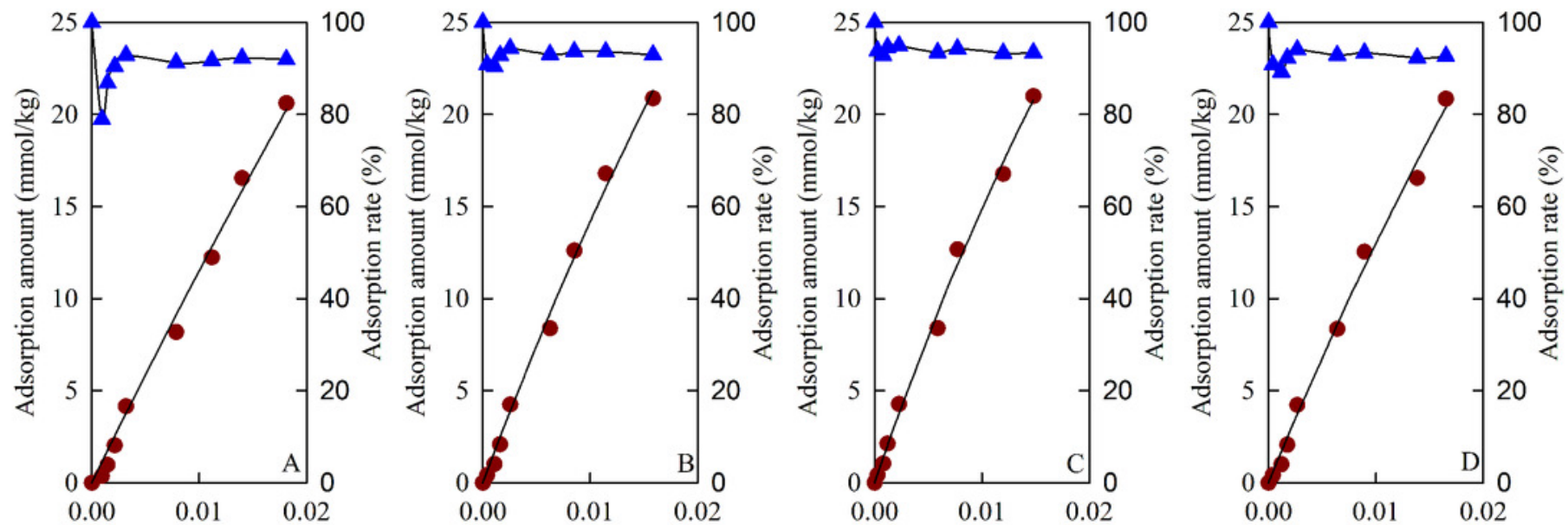

Equilibrum concentration $(\mathrm{mmol} / \mathrm{L})$ Equilibrum concentration $(\mathrm{mmol} / \mathrm{L})$ Equilibrum concentration $(\mathrm{mmol} / \mathrm{L})$ Equilibrum concentration $(\mathrm{mmol} / \mathrm{L})$
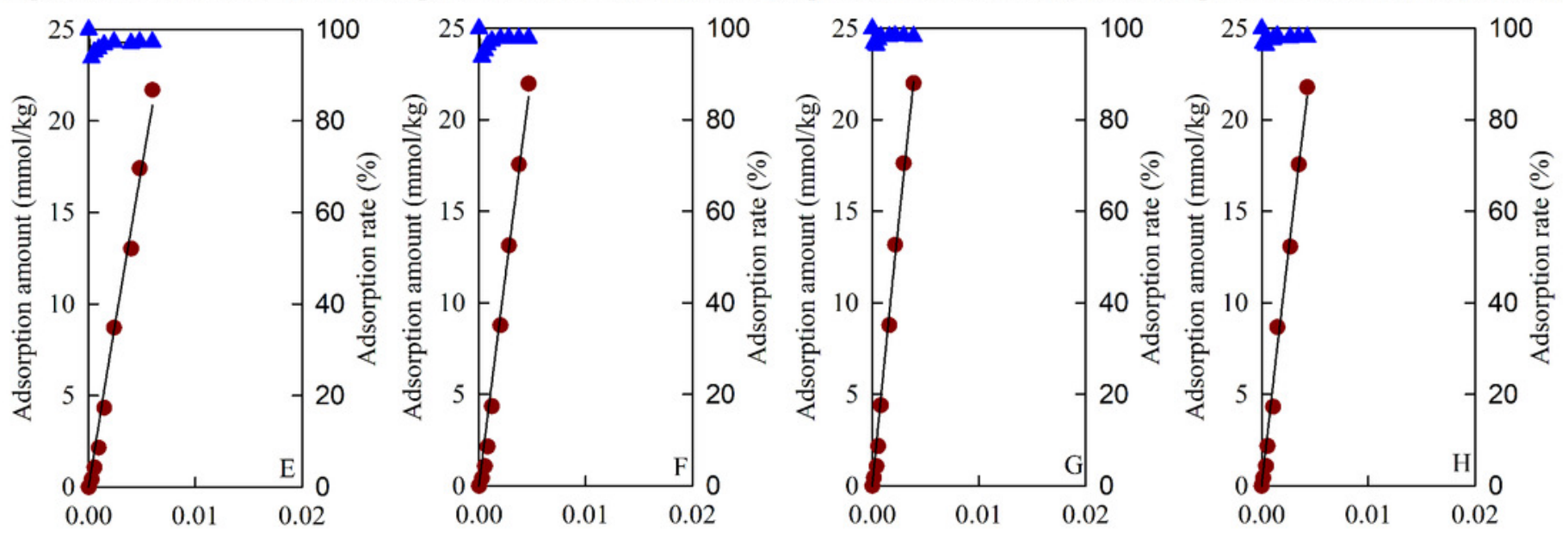

Equilibrum concentration $(\mathrm{mmol} / \mathrm{L})$ Equilibrum concentration $(\mathrm{mmol} / \mathrm{L})$ Equilibrum concentration $(\mathrm{mmol} / \mathrm{L})$ Equilibrum concentration $(\mathrm{mmol} / \mathrm{L})$

- Adsorption amount

$\Delta \quad$ Adsorption rate 
Figure 9

Adsorption differences of $\mathrm{Cu}^{2+}$ and TC on amphoteric-bentonite loaded magnetic-biochar

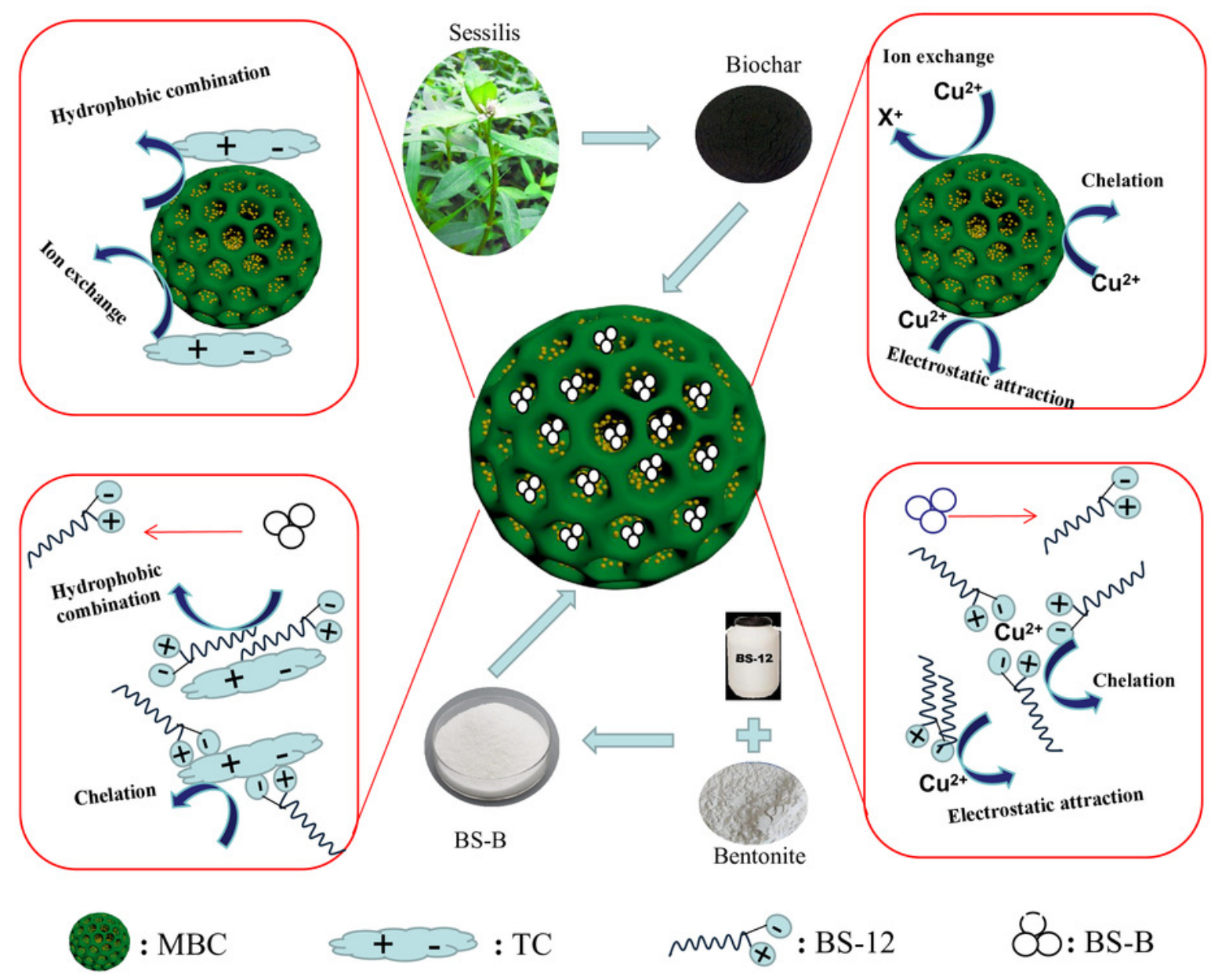


Figure 10

FTIR spectra of 100BS-B/MBC before and after $\mathrm{Cu}^{2+}$ and TC adsorption 100BS-B/MBC+Cu and 100BS-B/MBC+TC were 100BS-B/MBC have absorbed $\mathrm{Cu}^{2+}$ and TC, respectively .

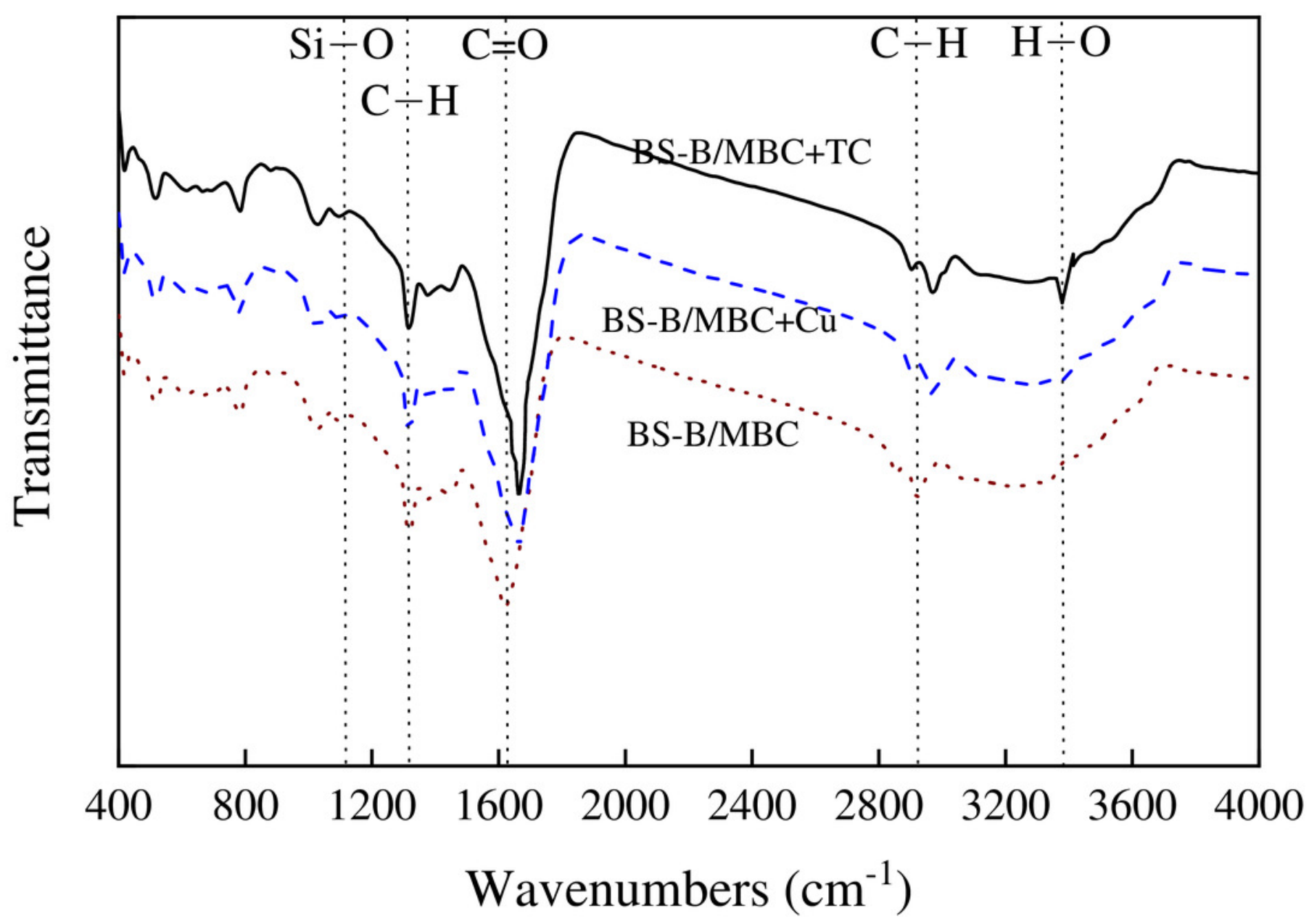

